\title{
Measurement report: Statistical modelling of long-term trends of atmospheric inorganic gaseous species within proximity of the pollution hotspot in South Africa
}

\author{
Jan-Stefan Swartz ${ }^{1}$, Pieter G. van Zyl ${ }^{1}$, Johan P. Beukes ${ }^{1}$, Corinne Galy-Lacaux ${ }^{2}$, Avishkar Ramandh ${ }^{3}$, and \\ Jacobus J. Pienaar ${ }^{1}$ \\ ${ }^{1}$ Atmospheric Chemistry Research Group, Chemical Resource Beneficiation, North-West University, \\ Potchefstroom, 2520, South Africa \\ ${ }^{2}$ Laboratoire d'Aérologie, Université de Toulouse, CNRS, UPS, 31400 Toulouse, France \\ ${ }^{3}$ Research and Technology, Sasol Technology (Pty) Limited, Sasolburg, 1947, South Africa
}

Correspondence: Pieter G. van Zyl (pieter.vanzyl@nwu.ac.za)

Received: 20 February 2020 - Discussion started: 6 April 2020

Revised: 8 July 2020 - Accepted: 31 July 2020 - Published: 11 September 2020

\begin{abstract}
South Africa is considered an important source region of atmospheric pollutants, which is compounded by high population and industrial growth. However, this region is understudied, especially with regard to evaluating longterm trends of atmospheric pollutants. The aim of this study was to perform statistical modelling of $\mathrm{SO}_{2}, \mathrm{NO}_{2}$ and $\mathrm{O}_{3}$ long-term trends based on 21-, 19- and 16-year passive sampling datasets available for three South African INDAAF (International Network to study Deposition and Atmospheric Chemistry in Africa) sites located within proximity of the pollution hotspot in the industrialized north-eastern interior in South Africa. The interdependencies between local, regional and global parameters on variances in $\mathrm{SO}_{2}, \mathrm{NO}_{2}$ and $\mathrm{O}_{3}$ levels were investigated in the model. Average monthly $\mathrm{SO}_{2}$ concentrations at Amersfoort (AF), Louis Trichardt (LT) and Skukuza (SK) were 9.91, 1.70 and $2.07 \mu \mathrm{g} \mathrm{m}^{-3}$, respectively, while respective mean monthly $\mathrm{NO}_{2}$ concentrations at each of these sites were 6.56, 1.46 and $2.54 \mu \mathrm{g} \mathrm{m}^{-3}$. Average monthly $\mathrm{O}_{3}$ concentrations were 50.77, 58.44 and $43.36 \mu \mathrm{g} \mathrm{m}^{-3}$ at AF, LT and SK, respectively. Long-term temporal trends indicated seasonal and inter-annual variability at all three sites, which could be ascribed to changes in meteorological conditions and/or variances in source contribution. Local, regional and global parameters contributed to $\mathrm{SO}_{2}$ variability, with total solar irradiation (TSI) being the most significant factor at the regional background site LT. Temperature $(T)$ was the most important factor at SK, lo-
\end{abstract}

cated in the Kruger National Park, while population growth $(P)$ made the most substantial contribution at the industrially impacted AF site. Air masses passing over the source region also contributed to $\mathrm{SO}_{2}$ levels at $\mathrm{SK}$ and LT. Local and regional factors made more substantial contributions to modelled $\mathrm{NO}_{2}$ levels, with $P$ being the most significant factor explaining $\mathrm{NO}_{2}$ variability at all three sites, while relative humidity $(\mathrm{RH})$ was the most important local and regional meteorological factor. The important contribution of $P$ on modelled $\mathrm{SO}_{2}$ and $\mathrm{NO}_{2}$ concentrations was indicative of the impact of increased anthropogenic activities and energy demand in the north-eastern interior of South Africa. Higher $\mathrm{SO}_{2}$ concentrations, associated with lower temperatures, as well as the negative correlation of $\mathrm{NO}_{2}$ levels to $\mathrm{RH}$, reflected the influence of pollution build-up and increased household combustion during winter. The El Niño-Southern Oscillation (ENSO) made a significant contribution to modelled $\mathrm{O}_{3}$ levels at all three sites, while the influence of local and regional meteorological factors was also evident. Trend lines for $\mathrm{SO}_{2}$ and $\mathrm{NO}_{2}$ at $\mathrm{AF}$ indicated an increase in $\mathrm{SO}_{2}$ and $\mathrm{NO}_{2}$ concentrations over the 19-year sampling period, while an upward trend in $\mathrm{NO}_{2}$ levels at $\mathrm{SK}$ signified the influence of growing rural communities. Marginal trends were observed for $\mathrm{SO}_{2}$ at $\mathrm{SK}$, as well as $\mathrm{SO}_{2}$ and $\mathrm{NO}_{2}$ at LT, while $\mathrm{O}_{3}$ remained relatively constant at all three sites. $\mathrm{SO}_{2}$ and $\mathrm{NO}_{2}$ concentrations were higher at $\mathrm{AF}$, while the regional $\mathrm{O}_{3}$ problem was evident at all three sites. 


\section{Introduction}

Although Africa is regarded as one of the most sensitive continents with regard to air pollution and climate change, it is the least studied (Laakso et al., 2012). South Africa is considered an important source region of atmospheric pollutants within the African continent, which is attributed to its highly industrialized economy with the most significant industrial activities including mining, metallurgical and petrochemical activities, as well as large-scale coal-fired electricity generation (Rorich and Galpin, 1998; Tiitta et al., 2014). Atmospheric pollution associated with South Africa is compounded by high population growth that, in turn, drives further economic and industrial growth leading to an everincreasing energy demand (Tiitta et al., 2014; World Bank, 2019; International Energy Agency, 2020). The extent of air pollution in South Africa is illustrated by the well-known $\mathrm{NO}_{2}$ pollution hotspot revealed by satellite data over the Mpumalanga Highveld, where 11 coal-fired power stations are located (Lourens et al., 2011), which was also recently indicated by the newly launched European Space Agency Sentinel-5P satellite (Meth, 2018).

The importance of long-term atmospheric chemical measurements has been indicated by numerous studies on atmosphere-biosphere interactions (Fowler et al., 2009) and air quality (Monks et al., 2009). These long-term assessments are crucial in identifying relevant policy requirements on local and global scales, as well as the most topical atmosphericchemistry research questions (Vet et al., 2014). In 1990, the International Global Atmospheric Chemistry (IGAC) programme, in collaboration with the Global Atmosphere Watch (GAW) network of the World Meteorological Organization (WMO) initiated the Deposition of Biogeochemically Important Trace Species (DEBITS) project with the aim to conduct long-term assessments of atmospheric biogeochemical species in the tropics - a region for which limited data existed (Lacaux et al., 2003). The programme is currently operated within the framework of the third phase of IGAC and within the context of the International Nitrogen Initiative (INI) programme. The African component of this initiative was historically referred to as IGAC DEBITS Africa (IDAF), which was relabelled in 2015/2016 as the International Network to study Deposition and Atmospheric Chemistry in Africa (INDAAF) programme. The INDAAF long-term network currently consists of 13 monitoring sites, strategically positioned in southern, western and central Africa, which are representative of the most important African ecosystems (http://indaaf.obs-mip.fr, last access: 12 October 2018). Typical measurements at the INDAAF sites include wet-only rain collection, aerosol composition and inorganic gaseous concentrations, determined with passive samplers.

Long-term measurements have been conducted at three dry-savannah southern African INDAAF sites, which include Amersfoort (AF), Louis Trichardt (LT) and Skukuza (SK) located within proximity of the pollution hotspot in the north- eastern interior of South Africa. Measurement of inorganic gaseous pollutant species, i.e. sulfur dioxide $\left(\mathrm{SO}_{2}\right)$, nitrogen dioxide $\left(\mathrm{NO}_{2}\right)$ and ozone $\left(\mathrm{O}_{3}\right)$, has been conducted since 1995 at LT, 1997 at AF and 2000 at SK utilizing passive samplers. These gaseous species are generally associated with the above-mentioned major sources of atmospheric pollutants in South Africa (Connell, 2005). Moreover, a large number of these sources are located within the north-eastern interior of South Africa and include the Mpumalanga Highveld, the Johannesburg-Pretoria conurbation and the Vaal Triangle. Laban et al. (2018), for instance, recently indicated high $\mathrm{O}_{3}$ levels in this north-eastern interior of South Africa, while it was also indicated that $\mathrm{O}_{3}$ formation in this region can be considered $\mathrm{NO}_{x}$-limited due to high $\mathrm{NO}_{2}$ concentrations. Therefore, the South African INDAAF sites were strategically positioned to be representative of the South African interior, with AF being an industrially influenced site, LT being a rural background site and SK being a background site located in the Kruger National Park, as indicated in Fig. 1.

A number of studies have been reported on measurements conducted within the INDAAF network (Martins et al., 2007; Adon et al., 2010, 2013; Josipovic et al., 2011), presenting inorganic gaseous concentrations at southern, as well as western and central, African sites, respectively. Conradie et al. (2016) recently reported on precipitation chemistry at the South African INDAAF sites, while Maritz et al. (2019) conducted an assessment of particulate organic and elemental carbon at these sites. However, in-depth analysis of longterm trends of atmospheric pollutants at the INDAAF sites has not been conducted due to the non-availability of longterm data. Therefore, the aim of this study was to perform statistical modelling of $\mathrm{SO}_{2}, \mathrm{NO}_{2}$ and $\mathrm{O}_{3}$ long-term trends based on 21-, 19- and 16-year datasets available for LT, AF and SK, respectively. The influences of sources together with local, regional and global meteorological patterns on the atmospheric concentrations of $\mathrm{SO}_{2}, \mathrm{NO}_{2}$ and $\mathrm{O}_{3}$ were considered in the model.

\section{Measurement site and experimental methods}

\subsection{Site description}

Detailed site descriptions have been presented in the literature, e.g. Mphepya et al. $(2004,2006)$ and Conradie et al. (2016). AF (1628 m above mean sea level, a.m.s.l.) and LT (1300 m a.m.s.l.) are located within the South African Highveld, while SK is situated in the South African Lowveld. As indicated in Fig. 1, AF is in close proximity to the major industrial activities in the Mpumalanga Highveld ( $\sim 50$ to $100 \mathrm{~km}$ north-west) and $\sim 200 \mathrm{~km}$ east of the Johannesburg-Pretoria conurbation. LT is located in a rural region mainly associated with agricultural activity, while SK 


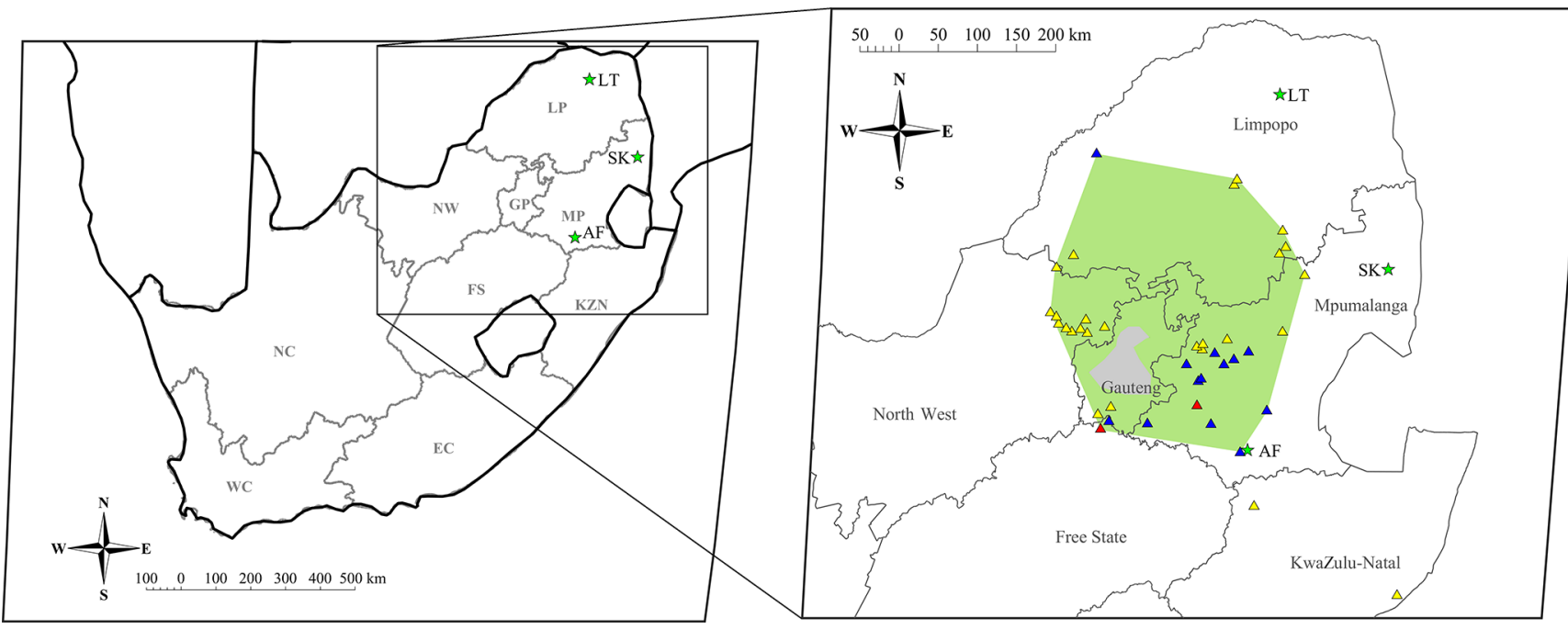

Figure 1. Regional map of South Africa indicating the measurement sites at Amersfoort (AF), Louis Trichardt (LT) and Skukuza (SK) with green stars. A zoomed-in map indicates the defined source region, the Johannesburg-Pretoria conurbation (grey polygon) and large point sources, i.e. power stations (blue triangles), petrochemical plants (red triangles) and pyrometallurgical smelters (yellow triangles).

(267 m a.m.s.l) is situated in the Kruger National Park, i.e. natural bushveld in a protected area.

A summary of the regional meteorology of the South African interior, especially relating to the north-eastern part, was presented by Laakso et al. (2012) and Conradie et al. (2016). Meteorology in the South African interior exhibits strong seasonal variability. This region is characterized by anticyclonic air mass circulation, which is especially predominant during winter, resulting in pronounced inversion layers trapping pollutants near the surface (Tyson et al., 1996; Garstang et al., 1996; Gierens et al., 2019). In addition, the north-eastern interior (as most parts of the South African interior) is also characterized by distinct wet and dry seasons, with the wet season occurring typically from mid-spring up to autumn (mid-October to mid-May) (Hewitson and Crane, 2006; Conradie et al., 2016).

In Fig. 2, the air mass history for LT, AF and SK for the entire sampling periods at each site is presented by means of overlaid back trajectories; $96 \mathrm{~h}$ back trajectories arriving hourly at each site at a height of $100 \mathrm{~m}$ were calculated with the Hybrid Single Particle Lagrangian Integrated Trajectory (HYSPLIT) model (version 4.8), developed by the National Oceanic and Atmospheric Administration (NOAA) Air Resources Laboratory (ARL) (Draxler and Hess, 2014).

Meteorological data were obtained from the Global Data Assimilation System (GDAS) archive of the National Centers for Environmental Prediction (NCEP) of the United States National Weather Service. Back trajectories were overlaid with fit-for-purpose programming software on a map area divided into grid cells of $0.2^{\circ} \times 0.2^{\circ}$. A colour scale presents the frequency of back trajectories passing over each grid cell, with dark blue indicating the lowest and dark red the highest percentage. The predominant anticyclonic air mass circulation over the interior of South Africa is reflected by the overlay back trajectories at each site, while it also indicates that $\mathrm{AF}$ is frequently impacted by air masses passing over the major sources in the north-eastern interior. In addition, it is also evident that the rural background sites (LT and SK) are also impacted by the regional circulation of air masses passing over the major sources.

\subsection{Sampling, analysis and data quality}

Passively derived $\mathrm{SO}_{2}, \mathrm{NO}_{2}$ and $\mathrm{O}_{3}$ concentrations were available from 1995 to 2015,1997 to 2015 and 2000 to 2015 for LT, AF and SK, respectively. Gaseous $\mathrm{SO}_{2}, \mathrm{NO}_{2}$ and $\mathrm{O}_{3}$ concentrations were measured utilizing passive samplers manufactured at the North-West University, which are based on the Ferm (1991) passive sampler. Detailed descriptions on the theory and functioning of these passive samplers, which are based on laminar diffusion and chemical reaction of the atmospheric pollutant of interest, have been presented in the literature (Ferm, 1991; Dhammapala, 1996; Martins et al., 2007; Adon et al., 2010). In addition, the passive samplers utilized in this study have been substantiated through a number of inter-comparison studies (Martins et al., 2007; He and Bala, 2008).

Samplers were exposed in duplicate sets for each gaseous species at each measurement site ( $1.5 \mathrm{~m}$ above ground level) for a period of approximately 1 month and returned to the laboratory for analysis. Blank samples were kept sealed in the containers for each set of exposed samplers. Prior to 2008, $\mathrm{SO}_{2}$ and $\mathrm{O}_{3}$ passive samples were analysed with a Dionex 100 Ion Chromatograph (IC), while $\mathrm{NO}_{2}$ samples were analysed with a Cary 50 ultraviolet-visible (UV/Vis) spectrometer up until 2012. $\mathrm{SO}_{2}$ and $\mathrm{O}_{3}$ samples collected 


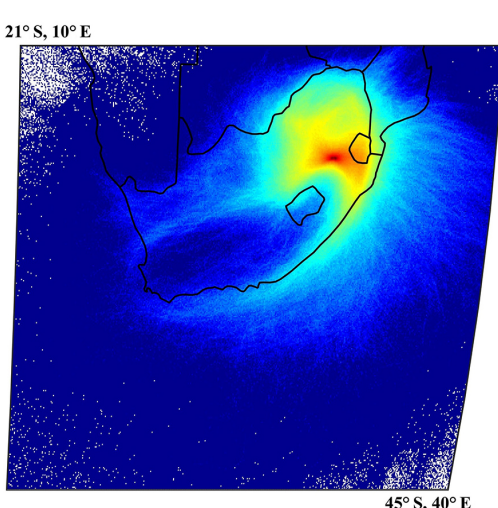

(a)
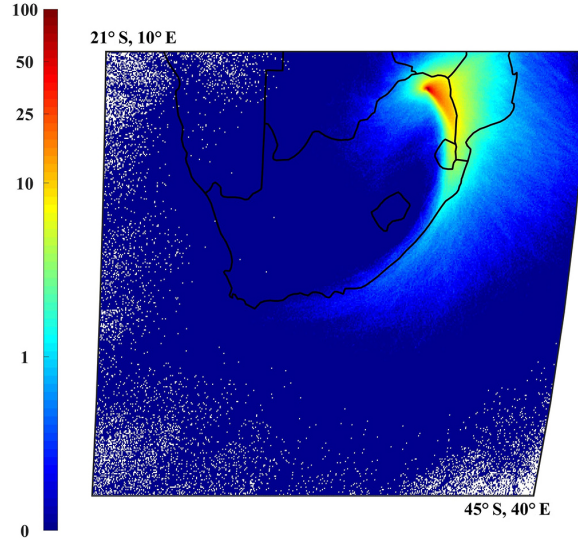

(b)
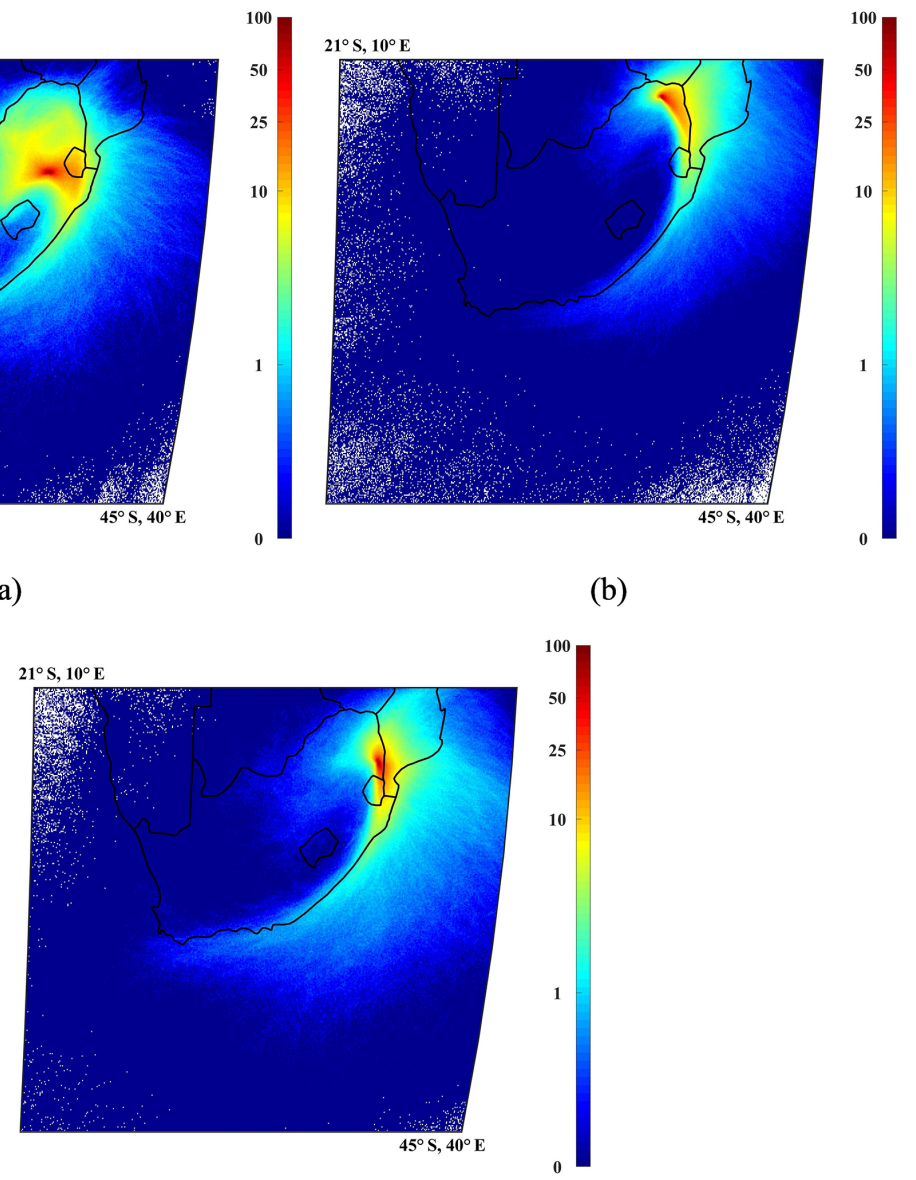

(c)

Figure 2. Overlaid hourly arriving $96 \mathrm{~h}$ back trajectories for air masses arriving at (a) AF from 1997 to 2015, (b) LT from 1995 to 2015 and (c) SK from 2000 to 2015.

after 2008, and $\mathrm{NO}_{2}$ samples collected after 2012, were analysed with a Dionex ICS-3000 system. Data quality of the analytical facilities is ensured through participation in the World Meteorological Organization (WMO) bi-annual Laboratory Intercomparison Study (LIS). The results of the 50th LIS study in 2014 indicated that the recovery of each ion in standard samples was between $95 \%$ and $105 \%$ (Conradie et al., 2016). Analysed data were also subjected to the $Q$ test, with a $95 \%$ confidence threshold to identify, evaluate and reject outliers in the datasets.

\subsection{Multiple linear regression model}

Similar to the approach employed by Swartz et al. (2020) for the Cape Point GAW station, a multiple linear regression (MLR) model was utilized to statistically evaluate the influence of sources and meteorology on the concentrations of $\mathrm{SO}_{2}, \mathrm{NO}_{2}$ and $\mathrm{O}_{3}$ at AF, LT and SK. This model was also utilized by Toihir et al. (2018) and Bencherif et al. (2006) for trend estimates of $\mathrm{O}_{3}$ and temperature, respectively. MLR analysis models the relationship between two or more in- dependent variables and a dependent variable by fitting a linear equation to the observed data, which can be utilized to calculate values for the dependent variable. In this study, concentrations of inorganic gaseous species $\left(\mathrm{SO}_{2}, \mathrm{NO}_{2}\right.$ and $\mathrm{O}_{3}$ ) were considered the dependent variable $(C(t))$, while local, regional and global factors were considered independent variables to yield the following general equation:

$C(t)=\sum_{k=1}^{p} a(k) \times f(t, k)+R^{\prime}(t)$,

where $f(t, k)$ describes the specific factor $k$ at time $t ; a(k)$ is the coefficient calculated by the model for the factor $k$ that minimizes the root mean square error (RMSE); and $R^{\prime}(t)$ is the residual term that accounts for factors that may have an influence on the model, which are not considered in the MLR model. The RMSE compares the calculated values with the measured values as follows:

$\chi^{2}=\left[\sum_{t} C(t)-\sum_{k} a(k) \times f(t, k)\right]^{2}$. 
The trend was parameterized as linear: trend $(t)=\alpha_{0}+\alpha_{1} \cdot t$, where $t$ denotes the time range, $\alpha_{0}$ is a constant, $\alpha_{1}$ is the slope of the trend $(t)$ line that estimates the trend over the timescale.

The significance of each of the independent variables on the calculated $C(t)$ was evaluated by the relative-importance weight (RIW) approach, which examines the relative contribution that each independent variable makes to the dependent variable and ranks independent variables in order of significance (Nathans et al., 2012; Kleynhans et al., 2017). The RIW approach was applied with IBM $^{\circledR}$ SPSS $^{\circledR}$ Statistics version 23, together with programme syntaxes and scripts adapted from Kraha et al. (2012) and Lorenzo-Seva et al. (2010).

\subsection{Input data}

Global meteorological factors considered in the model included total solar irradiation (TSI), the El Niño-Southern Oscillation (ENSO), the Indian Ocean Dipole (IOD), the quasi-biennial oscillation (QBO) and the Southern Annular Mode (SAM). Data for the ENSO and QBO cycles were obtained from the National Oceanic and Atmospheric Administration (NOAA) (NOAA, 2015a, b), while TSI and IOD data were obtained from the Royal Netherlands Meteorological Institute (Koninklijk Nederlands Meteorologisch Instituut) (KMNI, 2016a, b). SAM data were obtained from the National Environmental Research Council's British Antarctic Survey (Marshall, 2018). The initial input parameters for the model only included the global force factors in order to assess the importance of individual global predictors on measured gaseous concentrations.

Local and regional meteorological parameters included in the model were rain depth $(R)$, relative humidity $(\mathrm{RH})$ and ambient temperature $(T)$, as well as monthly averaged wind direction $\left(W_{\mathrm{d}}\right)$ and wind speed $\left(W_{\mathrm{s}}\right)$. Since meteorological parameters were not measured at the three sites during the entire sampling period, meteorological data were obtained from the European Centre for Medium-Range Weather Forecasts (ECMWF) reanalysis interim archive (ERA). Although meteorological measurements were conducted by the South African Weather Service within relative proximity of the locations of the three sites, the data coverage for all the meteorological parameters for the entire sampling period was relatively low $(<50 \%)$. Planetary boundary layer (PBL) heights were obtained from the global weather forecast model operated by the ECMWF (Korhonen et al., 2014). Population data $(P)$ from three separate national censuses were obtained from local municipalities and were also included in the model.

Daily fire distribution data from 2000 to 2015 were derived from the National Aeronautics and Space Administration's (NASA) Moderate Resolution Imaging Spectrometer (MODIS) satellite retrievals. MODIS is mounted on the polar-orbiting Earth Observation System's (EOS) Terra spacecraft and globally measures, among others, burn scars, fire and smoke distributions. This dataset was retrieved from the NASA Distributed Active Archive Centers (DAACs) (Kaufman et al., 2003). Fire events were separated into the categories of a local fire event (LFE), occurring within a $100 \mathrm{~km}$ radius from a respective site, and a regional fire event (DFE), taking place between 100 and $1000 \mathrm{~km}$ from each site.

Hourly arriving back trajectories (as discussed above) were also used to calculate the percentage time that air masses spent over a predefined source region (Fig. 1) before arriving at each of the sites for each month, which was also a parameter (source region; SR) included in the statistical model. The source region is a combination of source regions defined in previous studies, e.g. Jaars et al. (2014) and Booyens et al. (2019), which comprised the Mpumalanga Highveld, Vaal Triangle, the Johannesburg-Pretoria conurbation, the western and the eastern Bushveld Igneous Complex (Fig. 1).

Since data were not available for certain local and regional factors considered in the model for the entire sampling periods at AF, LT and SK and in an effort to include the optimum number of local and regional factors available for each site, modelled concentrations could not be calculated for the entire sampling periods when global, regional and local factors were included in the MLR model.

\section{Results}

Figures A1, A2 and A3 in Appendix A present the time series of monthly average $\mathrm{SO}_{2}, \mathrm{NO}_{2}$ and $\mathrm{O}_{3}$ concentrations measured at AF (1997-2015), LT (1995-2015) and SK (20002015). Seasonal and inter-annual variability associated with changes in the prevailing meteorology and source contributions will be evaluated and statistically assessed using a multiple linear regression model in subsequent sections.

\subsection{Seasonal and inter-annual variability}

In Figs. 3, 4 and 5, the monthly $\mathrm{SO}_{2}, \mathrm{NO}_{2}$ and $\mathrm{O}_{3}$ concentrations, respectively, at AF, LT and SK, determined for the entire sampling periods, are presented. Monthly variability in concentrations of these species at these three sites is expected. The north-eastern interior of South Africa, where these sites are located, is generally characterized by increased concentrations in pollutant species during the dry winter months (June to September) due to the prevailing meteorological conditions (Conradie et al., 2016). More pronounced inversion layers trap pollutants near the surface, which, in conjunction with increased anticyclonic recirculation and decreased wet deposition, leads to the build-up of pollutant levels (Conradie et al., 2016; Laban et al., 2018). In addition, increased household combustion for space heating during winter also contributes to higher levels of atmospheric 
pollutants, while open biomass burning (wildfires) is also a significant source of atmospheric species in late winter and spring (August to November). Species typically associated with biomass burning (open or household) include particulate matter (PM), $\mathrm{CO}$ and $\mathrm{NO}_{2}$, while household combustion can also contribute to $\mathrm{SO}_{2}$ emissions depending on the type of fuel consumed. $\mathrm{CO}$ and $\mathrm{NO}_{2}$ are also important precursors of tropospheric $\mathrm{O}_{3}$, which also lead to increased surface $\mathrm{O}_{3}$ concentrations, especially with increased photochemical activity in spring (Laban et al., 2018). From Fig. 3, it is evident that $\mathrm{SO}_{2}$ concentrations peaked in winter months at LT and $\mathrm{SK}$, while $\mathrm{SO}_{2}$ levels did not reveal significant monthly variability at $\mathrm{AF}$ throughout the year. $\mathrm{NO}_{2}$ and $\mathrm{O}_{3}$ concentrations at all three sites are higher during August to November, coinciding with open biomass burning. $\mathrm{NO}_{2}$ and $\mathrm{O}_{3}$ levels at AF do not reflect the influence of pollutant build-up in winter, although the whiskers in July do indicate more instances of higher $\mathrm{NO}_{2}$ concentrations. SK did indicate higher $\mathrm{NO}_{2}$ and $\mathrm{O}_{3}$ concentrations during June and July, while LT also had relatively higher $\mathrm{O}_{3}$ concentrations during July.

The inter-annual variability of $\mathrm{SO}_{2}, \mathrm{NO}_{2}$ and $\mathrm{O}_{3}$ levels is presented in Figs. 6, 7 and 8, respectively, for AF, LT and SK. Noticeable from the $\mathrm{SO}_{2}$ and $\mathrm{NO}_{2}$ inter-annual fluctuations at all three sites is that the annual average $\mathrm{SO}_{2}$ and $\mathrm{NO}_{2}$ concentrations decreased up until 2003/2004 and 2002, respectively, which is followed by a period during which levels of $\mathrm{SO}_{2}$ and $\mathrm{NO}_{2}$ increased up until 2009 and 2007, respectively. After 2009, annual average $\mathrm{SO}_{2}$ concentrations remained relatively constant, while $\mathrm{NO}_{2}$ showed relatively large interannual variability, with annual $\mathrm{NO}_{2}$ concentrations reaching a maximum in 2011 and 2012. These observed periods of decreased and increased $\mathrm{SO}_{2}$ and $\mathrm{NO}_{2}$ levels are also indicated by the 3-year moving averages of the annual mean $\mathrm{SO}_{2}$ and $\mathrm{NO}_{2}$ concentrations at all three sites. Since these trends are observed at all three sites, located several hundred kilometres apart in the north-eastern interior, these inter-annual trends seem real and not merely like a localized artefact. Furthermore, monthly $\mathrm{SO}_{2}$ and $\mathrm{NO}_{2}$ measurements conducted at the Cape Point Global Atmosphere Watch station on the western coast of South Africa also indicate similar periods of increase and decrease in $\mathrm{SO}_{2}$ and $\mathrm{NO}_{2}$ levels (Swartz et al., 2020). Although annual $\mathrm{O}_{3}$ concentrations indicate inter-annual variances, annual average $\mathrm{O}_{3}$ concentrations remained relatively constant at all three sites, with the exception of a decreasing trend observed from 1995 to 2001 at LT, corresponding to the period during which $\mathrm{SO}_{2}$ and $\mathrm{NO}_{2}$ decreased. Similar to seasonal variances, inter-annual fluctuations can also be ascribed to changes in meteorological conditions and/or variances in source contribution. Conradie et al. (2016), for example, indicated that rain samples collected from 2009 to 2014 at these three sites had higher $\mathrm{SO}_{4}^{2-}$ and $\mathrm{NO}_{3}^{-}$concentrations compared to rain samples collected in 1986 to 1999 and 1999 to 2002, which is attributed to increased energy demand and a larger vehicular fleet associated with economic and population growth.

\subsection{Statistical modelling of variability}

\subsubsection{Sulfur dioxide $\left(\mathrm{SO}_{2}\right)$}

The $\mathrm{SO}_{2}$ concentrations calculated with the MLR model are compared to measured $\mathrm{SO}_{2}$ levels in Fig. 9 for AF (Fig. 9a), LT (Fig. 9b) and SK (Fig. 9c). In each panel, the RMSE differences between measured and modelled $\mathrm{SO}_{2}$ concentrations are presented as a function of the number of independent variables included in the model ( $\mathrm{i}$ and ii), while the differences between modelled and measured $\mathrm{SO}_{2}$ levels for each sample are also indicated (iii). As indicated above, in the initial run of the model, only global factors were included (i and iii), after which all factors (local, regional and global) were incorporated in the model (ii and iii). In Table 1, the coefficients and RIW\% of each of the independent variables are included in the optimum MLR equation containing all global factors, as well as in the optimum MLR equation when all local, regional and global factors are included. It is evident from Fig. 9a.iii, b.iii and c.iii that the correlations between measured and modelled $\mathrm{SO}_{2}$ levels are significantly improved when all factors are considered in the MLR model compared to only including global factors at all three sites. The $R^{2}$ values are improved from 0.122 to $0.330,0.078$ to 0.257 and 0.100 to 0.389 at AF, LT and SK, respectively. Although relatively weak correlations are observed between modelled and measured $\mathrm{SO}_{2}$ levels, the general trend of the measured $\mathrm{SO}_{2}$ concentrations is mimicked by the modelled values, even when only global factors are included in the MLR model. In addition, the $R^{2}$ values at $\mathrm{AF}$ and SK when all factors are considered (0.330 and 0.389$)$ can be considered moderate correlations (Kleynhans et al., 2017). It also seems that very high and low $\mathrm{SO}_{2}$ levels are underestimated by the model. Swartz et al. (2020) attributed differences between monthly concentrations of species measured with passive samplers at Cape Point (CPT) GAW and modelled levels to the limitations associated with the use of passive samplers.

The interdependencies between TSI and QBO at AF and LT, as well as TSI and IOD at SK, yielded the largest decreases in RMSE when only global parameters were considered. The RIW\% calculated for these parameters in the optimum MLR equation containing all global factors also indicates that these factors are the most significant. When all factors (local, regional and global) were considered in the model, the combinations between $P$, TSI, SR and $T$ at AF; TSI, SR, IOD and $R$ at LT; and $T$, TSI, $P$ and $W_{\mathrm{s}}$ at SK contributed to the most significant decrease in RMSE for each of the sites. According to the RIW\% calculated for each parameter in the optimum MLR equation containing all factors $P(54.5 \%)$ and TSI $(14.6 \%)$ at AF; TSI (34.7\%), SR $(11.3 \%), T(9.9 \%)$ and IOD $(8.0 \%)$ at LT; and $T(15.9 \%)$, TSI $(12.0 \%)$, SR $(9.9 \%), P(9.1 \%)$ and $W_{\mathrm{s}}(9.1 \%)$ at SK were the most important factors contributing to variances. From the MLR model, it is evident that global meteorological factors contribute to $\mathrm{SO}_{2}$ variability at each of these sites lo- 


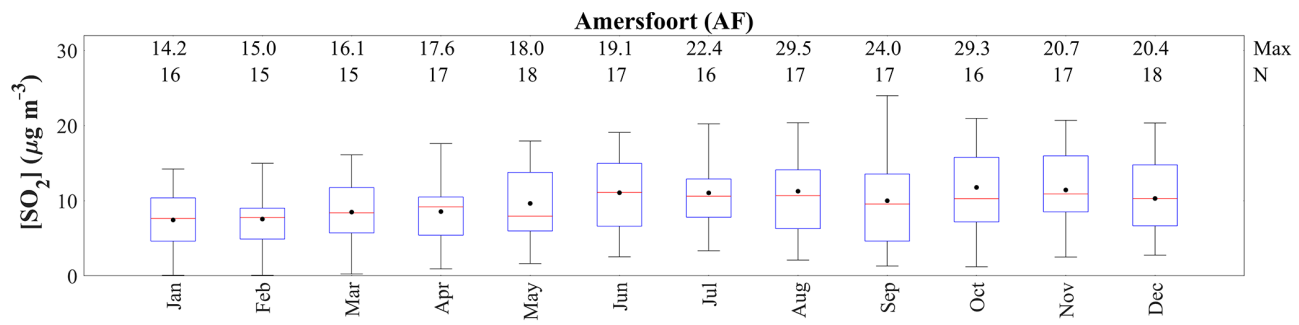

(a)

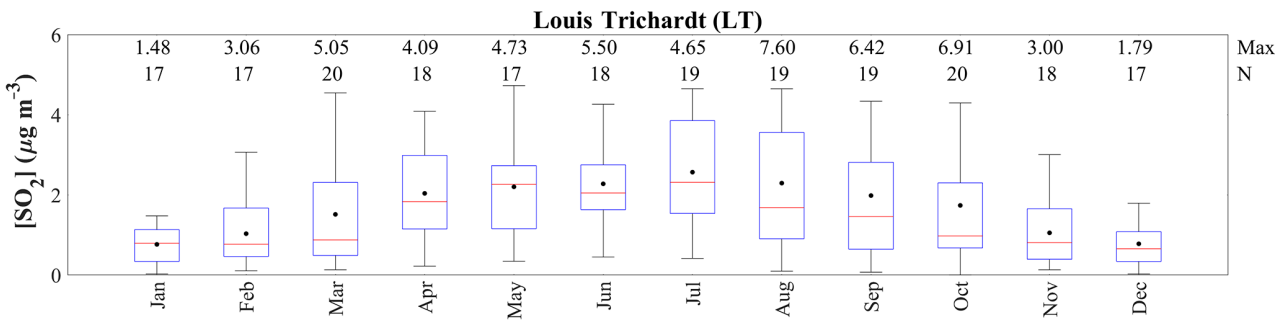

(b)

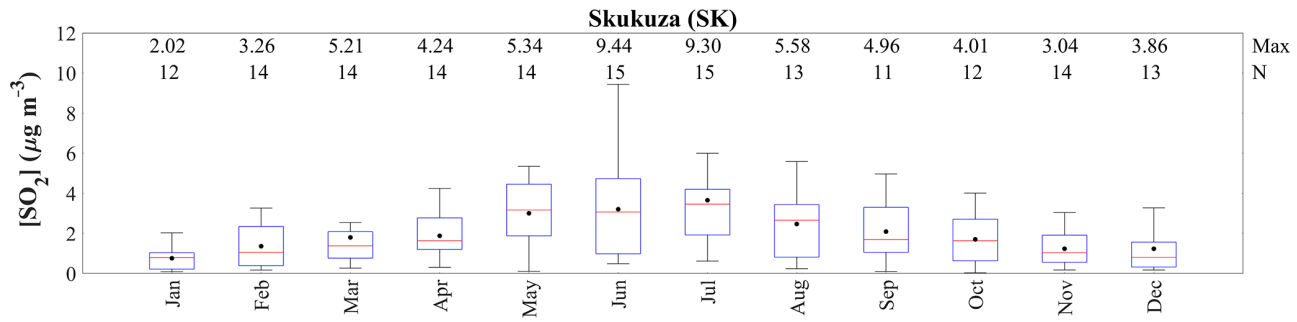

(c)

Figure 3. Monthly $\mathrm{SO}_{2}$ concentrations measured at (a) AF from 1997 to 2015, (b) LT from 1995 to 2015 and (c) SK from 2000 to 2015. The red line of each box represents the median; the top and bottom edges of the box represent the 25th and 75th percentiles, respectively; the whiskers are $\pm 2.7 \sigma$ (99.3\% coverage if the data have a normal distribution); and the black dots represent the averages. The maximum concentrations and the number of measurements $(N)$ are presented at the top.

cated in the north-eastern interior of South Africa. The model also indicates that the influence of global factors is more significant at the rural background site LT, where TSI made the largest contribution to the modelled value, while IOD also made a relatively important contribution. Although TSI was the second most significant factor at AF and SK, local and regional parameters were more important to variances in modelled $\mathrm{SO}_{2}$ levels at these sites.

Population growth had the most substantial contribution to the dependent variable at the industrially influenced AF, which is indicative of the impacts of increased anthropogenic activities and energy demand in this region. Therefore, it is most likely that the observed inter-annual variability observed at $\mathrm{AF}$, i.e. periods of decreased and increased $\mathrm{SO}_{2} \mathrm{lev}$ els, can mainly be attributed to changes in source contribution. The decrease in $\mathrm{SO}_{2}$ concentrations up until 2003/2004 is associated with a period following 1994 (when the new democracy was established), during which many companies obtained environmental accreditation (ISO 14000 series; ISO, 2015) and implemented mitigation technologies in or- der to comply with international trade requirements, e.g. certain large metallurgical smelters applied desulfurization technologies (e.g. Westcott et al., 2007). The period was characterized by an increased awareness of air pollution and its impacts in South Africa. However, it seems that these improvements made with regard to air pollution were offset from 2003/2004 due to rapid economic growth associated with increased industrial activities, e.g. increased production by pyrometallurgical industries (ICDA, 2012), as well as the increase in population growth accompanied by higher energy demand (Vet et al., 2014). In Fig. A4, the South African population and GDP (gross domestic product) from 1995 to 2015 according to the World Bank (World Bank, 2019) are presented together with the electricity generation (EG) in South Africa during this period as indicated by the International Energy Agency (International Energy Agency, 2020). A continuous growth in population is observed from 1995 to 2015, while the GDP trend reflects economic growth during this period corresponding to the observed periods of decreased and increased $\mathrm{SO}_{2}$ concentrations. A general 


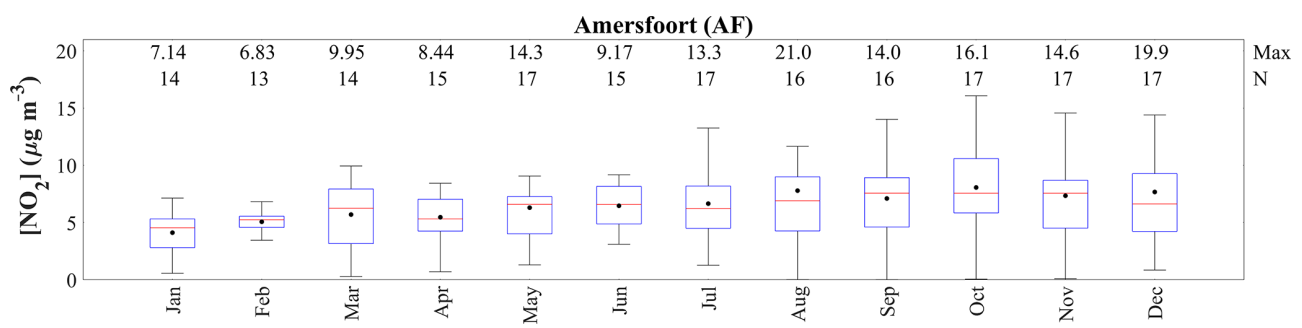

(a)

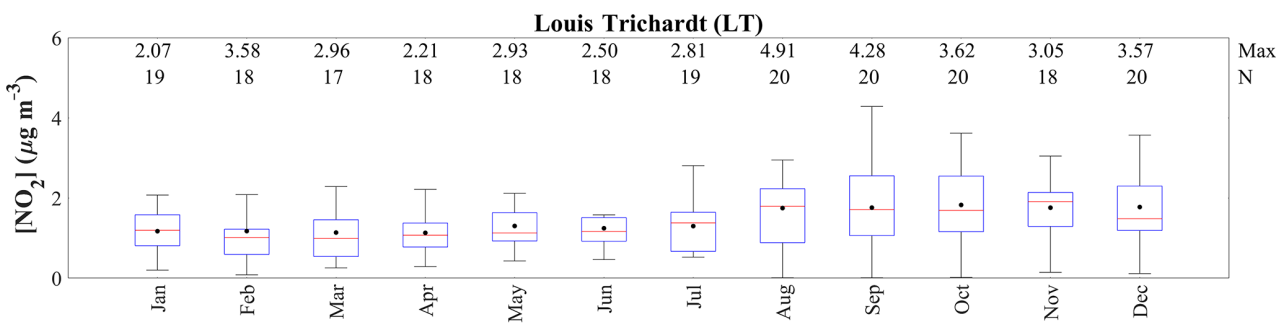

(b)

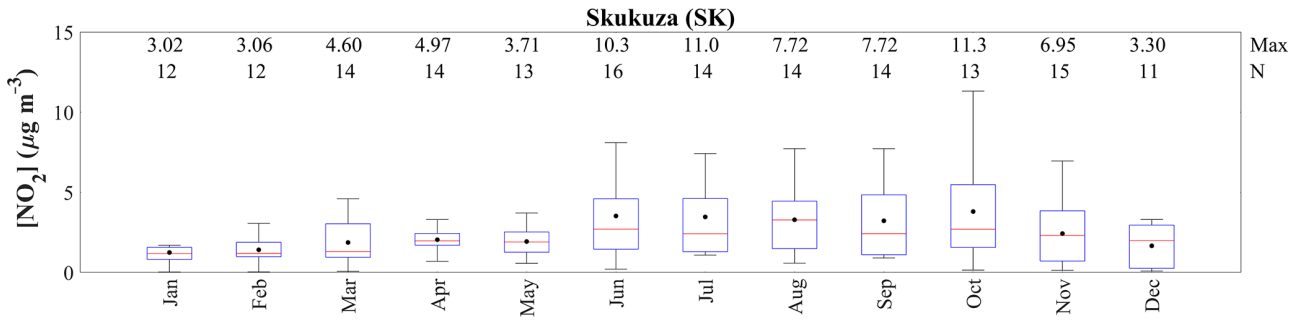

(c)

Figure 4. Monthly $\mathrm{NO}_{2}$ concentrations measured at (a) AF from 1997 to 2015, (b) LT from 1995 to 2015 and at (c) SK from 2000 to 2015. The red line of each box represents the median; the top and bottom edges of the box represent the 25th and 75th percentiles, respectively; the whiskers are $\pm 2.7 \sigma$ (99.3\% coverage if the data have a normal distribution); and the black dots represent the averages. The maximum concentrations and the number of measurements $(N)$ are presented at the top.

increase in electricity production over this period is also evident. Electricity consumption is a good indicator of increased anthropogenic activities, with Inglesi-Lotz and Blignaut (2011) indicating that electricity consumption in South Africa increased by $131024 \mathrm{GWh}$ from 1993 to 2006. In 2007/2008, the global financial crisis occurred, which forced numerous South African commodity-based producers (e.g. platinum group metal, base metal, ferrochromium, ferromanganese, ferrovanadium and steel smelters) to completely discontinue production. Ferrochromium production in South Africa, for instance, decreased by approximately $35 \%$ from 2007 to 2009 (ICDA, 2013), while energy consumption in the manufacturing sector dropped by approximately $34 \%$ from 2007 to 2008 (Statistics South Africa, 2012). Furthermore, these variances in source contribution associated with anthropogenic activities are also observed at LT and SK, distant from the major sources, due to these sites also being impacted by the regional circulation of air masses passing over major sources, as indicated in Fig. 2. In addition, the RIW\% associated with $P(9.1 \%)$ in the optimum MLR equa- tion containing all factors at SK is also indicative of not only the influence of population growth within the source region (Fig. 1) but also the increased populations of rural communities on the border of the Kruger National Park. Maritz et al. (2019) attributed higher organic and elemental carbon concentrations measured at SK to increased household biomass burning by these rural communities.

Temperature had the largest contribution to the variances of the modelled $\mathrm{SO}_{2}$ at $\mathrm{SK}$, while it was also an important parameter at LT. In addition, the source region (SR) factor made significant contributions to the dependent variable at SK and LT, while it also made a relative contribution at AF. These two factors are indicative of the influence of changes in local and regional meteorological conditions on $\mathrm{SO}_{2}$ concentrations, as well as the important influence of air mass movement over the source region. The contribution of SR at all the sites indicated that months and/or years coinciding with these sites being more frequently impacted by air masses passing over the defined source region (Fig. 1) corresponded to increased $\mathrm{SO}_{2}$ concentrations, while it also sub- 


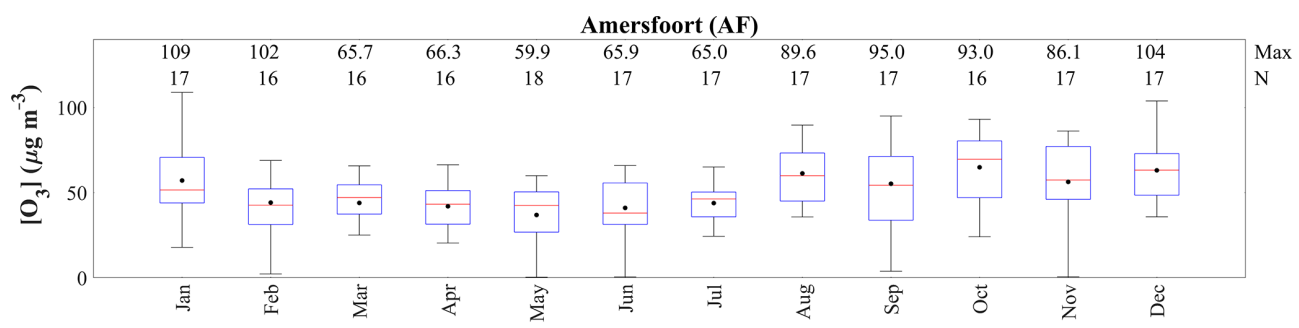

(a)

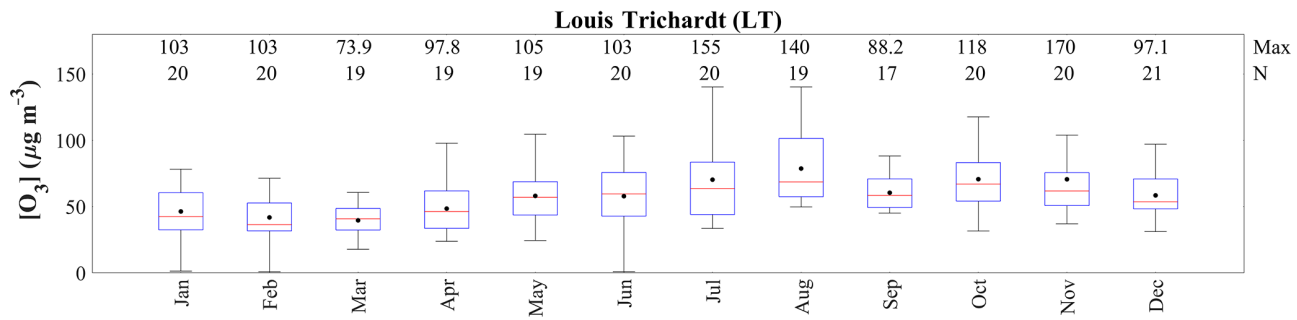

(b)

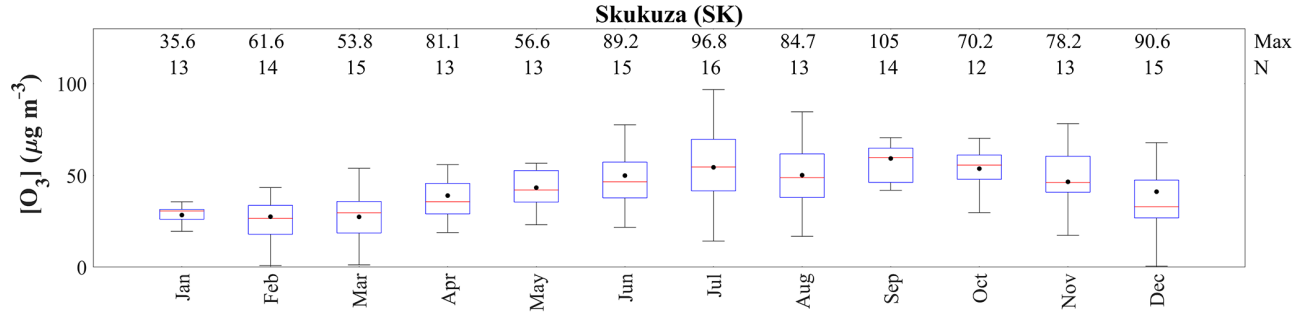

(c)

Figure 5. Monthly $\mathrm{O}_{3}$ concentrations measured at (a) AF from 1997 to 2015, (b) LT from 1995 to 2015 and (c) SK from 2000 to 2015. The red line of each box represents the median; the top and bottom edges of the box represent the 25th and 75th percentiles, respectively; the whiskers are $\pm 2.7 \sigma$ (99.3\% coverage if the data have a normal distribution); and the black dots represent the averages. The maximum concentrations and the number of measurements $(N)$ are presented at the top.

stantiates the aforementioned deduction that increased anthropogenic activities in the source region also influenced LT and SK. As indicated in Sect. 3.1, SK and LT revealed the expected higher $\mathrm{SO}_{2}$ levels during winter, while $\mathrm{AF}$ had a less distinct seasonal pattern. Therefore, the strong negative correlation between temperature and modelled $\mathrm{SO}_{2}$ concentrations at $\mathrm{SK}$ and $\mathrm{LT}$, i.e. higher $\mathrm{SO}_{2}$ levels associated with lower temperature, reflects the influence of local and regional meteorology on monthly $\mathrm{SO}_{2}$ variability, i.e. build-up of pollutant concentrations during winter. At SK, the influence of local meteorology is also indicated by the relatively strong negative correlation to $W_{\mathrm{s}}$, i.e. more stable conditions in winter coinciding with higher $\mathrm{SO}_{2}$ concentrations. Furthermore, the influence of the rural communities in proximity of SK on $\mathrm{SO}_{2}$ levels is also signified by $T$ being the most significant factor contributing to modelled $\mathrm{SO}_{2}$ values at this site. The less distinct seasonal pattern at $\mathrm{AF}$ can be attributed to the proximity of $\mathrm{AF}$ to the industrial $\mathrm{SO}_{2}$ sources, with the major point sources consistently emitting the same levels of $\mathrm{SO}_{2}$ throughout the year. Therefore, the average monthly
$\mathrm{SO}_{2}$ concentrations measured with passive samplers at $\mathrm{AF}$ do not reflect the influence of local and regional meteorology on atmospheric $\mathrm{SO}_{2}$ concentrations.

The slopes of the trend lines of $\mathrm{SO}_{2}$ values calculated when only global factors were included in the model did not correspond with the trend lines of the measured $\mathrm{SO}_{2}$ concentrations at all the sites, with the exception of LT that showed slightly better correlations, signifying the stronger influence of global factors at this site (Fig. 9a.iii, b.iii and c.iii). However, the slopes of the linear regression trend lines for the measured $\mathrm{SO}_{2}$ concentrations and the modelled $\mathrm{SO}_{2}$ levels when all the factors are included in the model are exactly the same at AF, LT and SK when the same period is considered for both the modelled and measured values. A positive slope for the 19-year trend line for measured $\mathrm{SO}_{2}$ concentrations is observed at $\mathrm{AF}$ (Fig. 9a.iii), indicating an increase in $\mathrm{SO}_{2}$ levels over the 19-year sampling period, i.e. $0.43 \mu \mathrm{g} \mathrm{m}^{-3} \mathrm{yr}^{-1}$. An increase in $\mathrm{SO}_{2}$ concentration, i.e. $0.09 \mu \mathrm{g} \mathrm{m}^{-3} \mathrm{yr}^{-1}$, is also determined for the 16-year measurement period at SK (Fig. 9b.iii), which is 


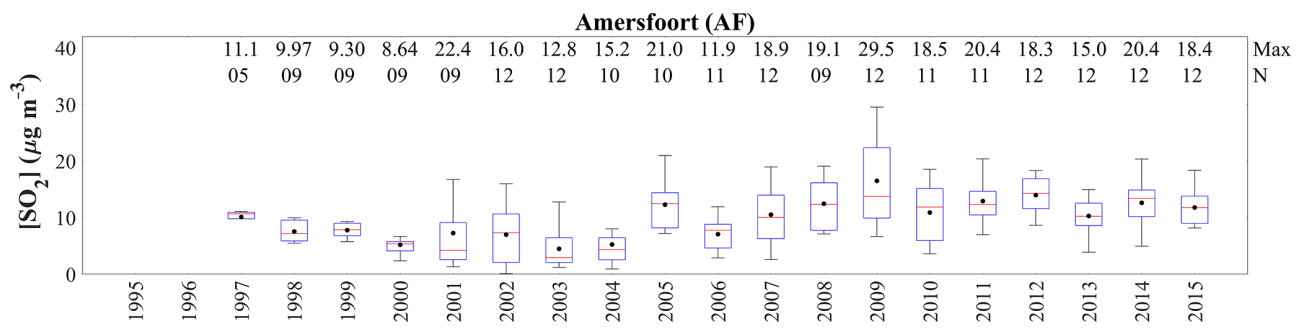

(a)

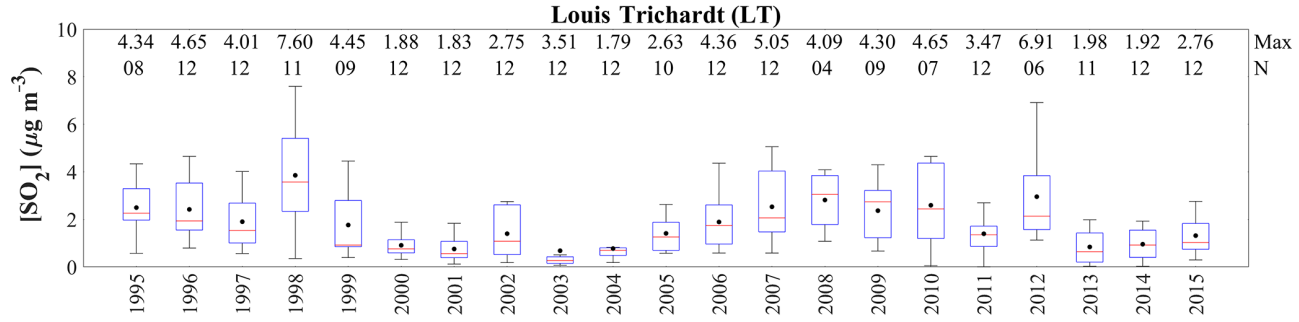

(b)

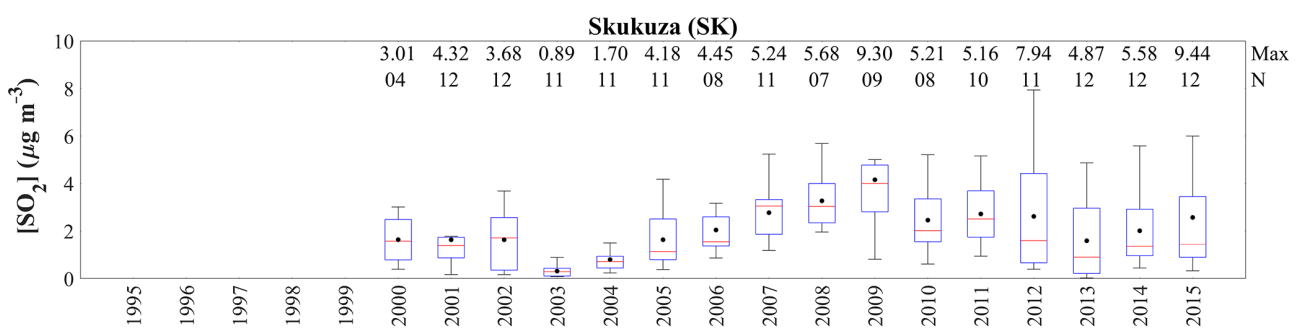

(c)

Figure 6. Annual $\mathrm{SO}_{2}$ concentrations at (a) AF, (b) LT and (c) SK. The red line of each box represents the median; the top and bottom edges of the box represent the 25th and 75th percentiles, respectively; the whiskers are $\pm 2.7 \sigma(99.3 \%$ coverage if the data have a normal distribution); and the black dots represent the averages. The maximum concentrations and the number of measurements $(N)$ are presented at the top.

significantly smaller than the upward trend at AF. In contrast to AF and SK, LT indicates a slight net negative slope with $\mathrm{SO}_{2}$ decreasing on average by $0.03 \mu \mathrm{g} \mathrm{m}^{-3} \mathrm{yr}^{-1}$ during the 21-year sampling period (Fig. 9c.iii). The 19- and 21-year datasets at AF and LT also allowed for the calculation of decadal trends, which were determined to be $5.24 \mu \mathrm{g} \mathrm{m}^{-3}$ per decade (average $\mathrm{SO}_{2}$ concentrations from 1997 to 2006 were $7.20 \mu \mathrm{g} \mathrm{m}^{-3}$, and average $\mathrm{SO}_{2}$ concentrations from 2007 to 2015 were $12.44 \mu_{g^{-3}}$ ) and $0.18 \mu \mathrm{g} \mathrm{m}^{-3}$ per decade (average $\mathrm{SO}_{2}$ concentrations from 1995 to 2004 were $1.64 \mu \mathrm{g} \mathrm{m}^{-3}$, and average $\mathrm{SO}_{2}$ concentrations from 2005 to 2014 were $1.82 \mu \mathrm{g} \mathrm{m}^{-3}$ ), respectively, for the 2 decades. Trend lines are also presented for the periods characterized by increased $(1995,1997$ to 2003) and decreased (2004 to 2008/2009) $\mathrm{SO}_{2}$ concentrations at LT and AF. The average annual trend between 1997 and 2003 at AF was $-0.53 \mu \mathrm{g} \mathrm{m}^{-3} \mathrm{yr}^{-1}$, while the annual trend from 2004 to 2009 was $1.87 \mu \mathrm{g} \mathrm{m}^{-3} \mathrm{yr}^{-1}$. At LT, the average annual $\mathrm{SO}_{2}$ concentrations decreased by $-0.26 \mu \mathrm{g} \mathrm{m}^{-3} \mathrm{yr}^{-1}$ from
1995 to 2002 and increased by $0.37 \mu \mathrm{g} \mathrm{m}^{-3} \mathrm{yr}^{-1}$ from 2003 to 2007 .

\subsubsection{Nitrogen dioxide $\left(\mathrm{NO}_{2}\right)$}

In Fig. 10, the measured $\mathrm{NO}_{2}$ concentrations are related to the modelled $\mathrm{NO}_{2}$ levels, while Table 2 presents the coefficients and RIW\% of each of the independent variables included in the optimum MLR equation modelling $\mathrm{NO}_{2}$ concentrations. Similar to $\mathrm{SO}_{2}$, the relationships between measured and modelled $\mathrm{NO}_{2}$ are also significantly improved when local, regional and global factors are included in the model at all three sites (Fig. 10a.iii, b.iii and c.iii). However, inclusion of only global factors in the model yielded modelled $\mathrm{NO}_{2}$ concentrations that mimicked the general measured $\mathrm{NO}_{2}$ trend. The $R^{2}$ values, when only global factors are included, i.e. $0.171,0.170$ and 0.099 at AF, LT and SK, respectively, are enhanced to $0.498,0.468$ and 0.362 at AF, LT and SK, respectively, when all factors are considered in the MLR model. The $R^{2}$ values, when all factors are included, 


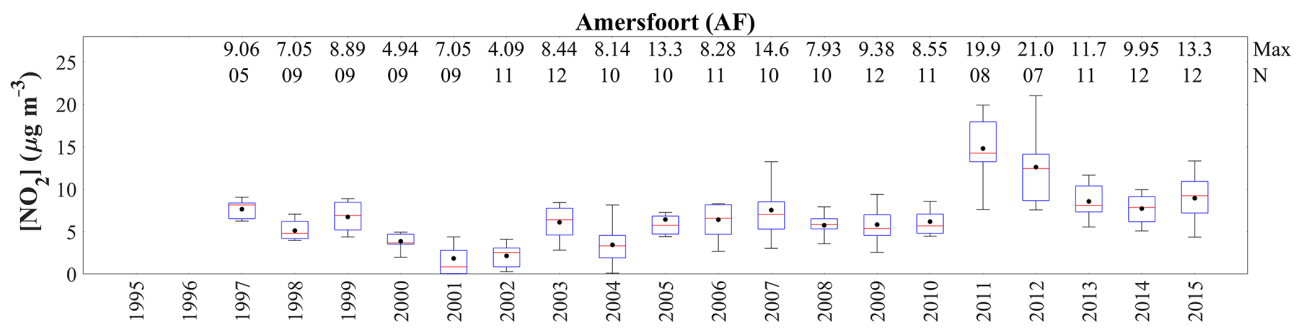

(a)

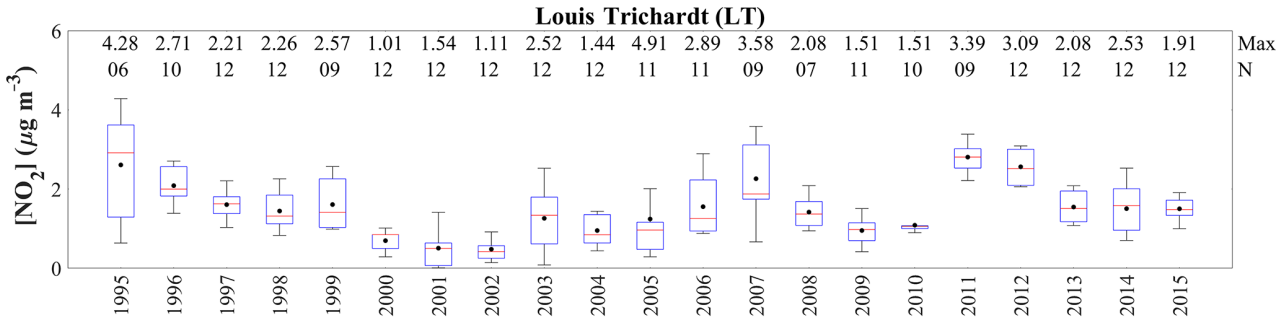

(b)

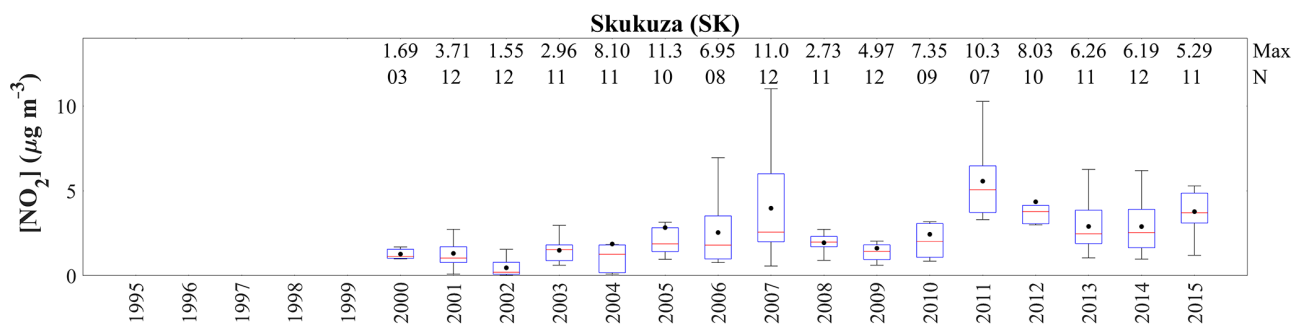

(c)

Figure 7. Annual $\mathrm{NO}_{2}$ concentrations at (a) AF, (b) LT and (c) SK. The red line of each box represents the median; the top and bottom edges of the box represent the 25th and 75th percentiles, respectively; the whiskers are $\pm 2.7 \sigma(99.3 \%$ coverage if the data have a normal distribution); and the black dots represent the averages. The maximum concentrations and the number of measurements $(N)$ are presented at the top.

especially AF and LT, can be considered relatively good correlations (Sheskin, 2003). In general, modelled $\mathrm{NO}_{2}$ concentrations corresponded well with the observed variances in measured $\mathrm{NO}_{2}$ levels when all factors are included in the model at all three sites, with the exception of very high $\mathrm{NO}_{2}$ concentrations.

The annual trend calculated from the slope of the 19-year measured $\mathrm{NO}_{2}$ dataset at $\mathrm{AF}$ indicates an annual increase of $0.33 \mu \mathrm{g} \mathrm{m}^{-3} \mathrm{yr}^{-1}$, while the 16-year measured $\mathrm{NO}_{2}$ concentrations indicate an upward trend of $0.19 \mu \mathrm{g} \mathrm{m}^{-3} \mathrm{yr}^{-1}$ at SK. The trend line of measured $\mathrm{NO}_{2}$ concentrations at LT also indicated a marginal increase, i.e. $0.02 \mu \mathrm{g} \mathrm{m}^{-3} \mathrm{yr}^{-1}$ in $\mathrm{NO}_{2}$ levels over the 21-year sampling period. Decadal trends were determined to be $3.43 \mu \mathrm{g} \mathrm{m}^{-3}$ per decade (average $\mathrm{NO}_{2}$ concentrations from 1997 to 2006 were $4.86 \mu \mathrm{g} \mathrm{m}^{-3}$, and average $\mathrm{NO}_{2}$ concentrations from 2007 to 2015 were $8.29 \mu \mathrm{g} \mathrm{m}^{-3}$ ) and $0.45 \mu \mathrm{g} \mathrm{m}^{-3}$ per decade (average $\mathrm{NO}_{2}$ concentrations from 1995 to 2004 were $1.23 \mu \mathrm{g} \mathrm{m}^{-3}$, and average $\mathrm{NO}_{2}$ concentrations from 2005 to 2014 were
$1.68 \mathrm{\mu g} \mathrm{m}^{-3}$ ), respectively, for the 2 decades. Trend lines were also calculated for the periods coinciding with increases and decreases in measured $\mathrm{NO}_{2}$ concentrations at $\mathrm{AF}$ and LT. The average annual trend between 1997 and 2003 at AF was $-0.26 \mu \mathrm{g} \mathrm{m}^{-3} \mathrm{yr}^{-1}$, while the annual trend from 2004 to 2009 was $0.37 \mu \mathrm{g} \mathrm{m}^{-3} \mathrm{yr}^{-1}$. At LT, the average annual $\mathrm{NO}_{2}$ concentrations decreased by $-0.29 \mu \mathrm{g} \mathrm{m}^{-3} \mathrm{yr}^{-1}$ from 1995 to 2002 and increased by $0.28 \mathrm{\mu g} \mathrm{m}^{-3} \mathrm{yr}^{-1}$ from 2003 to 2007. Similar to $\mathrm{SO}_{2}$, the slopes of the linear regression trend lines for the measured $\mathrm{NO}_{2}$ concentrations and the modelled $\mathrm{NO}_{2}$ levels when all the factors are included in the model are exactly the same at AF, LT and SK (Fig. 10a.iii, b.iii and c.iii). However, with the exception of LT, the slopes of the trend lines of $\mathrm{NO}_{2}$ levels calculated including only global factors in the model did not correspond with the trend lines of the measured $\mathrm{NO}_{2}$ concentrations, indicating the significance of local and regional factors on measured $\mathrm{NO}_{2}$ concentrations (Fig. 10a.iii, b.iii and c.iii). 


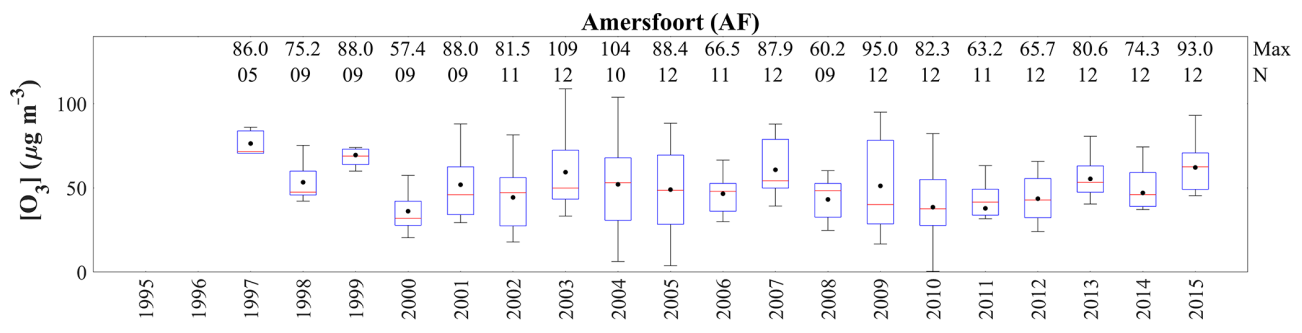

(a)

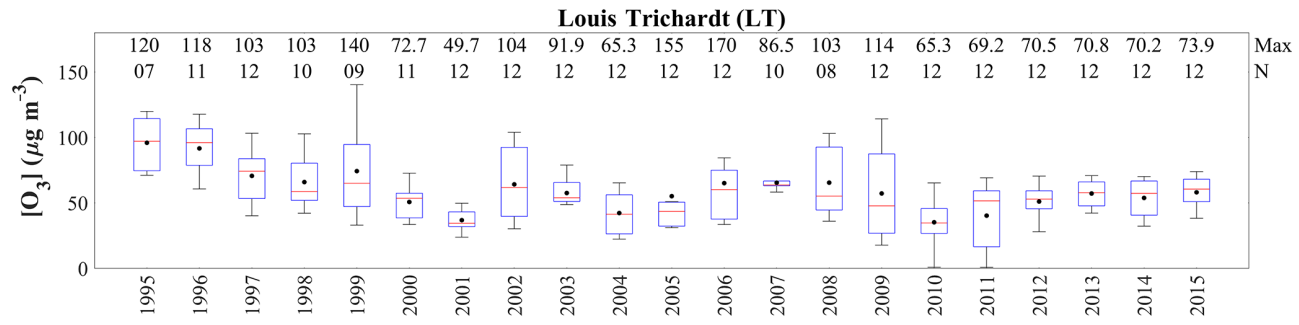

(b)

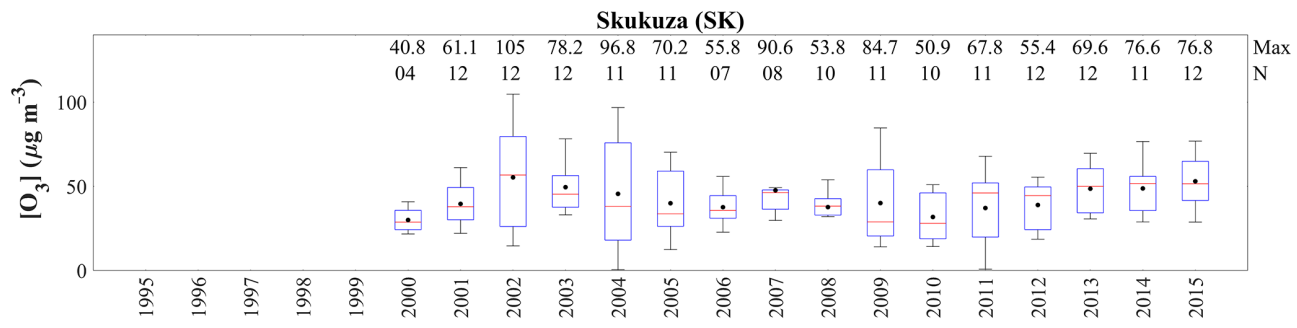

(c)

Figure 8. Annual $\mathrm{O}_{3}$ concentrations at (a) AF, (b) LT and (c) SK. The red line of each box represents the median; the top and bottom edges of the box represent the 25th and 75th percentiles, respectively; the whiskers are $\pm 2.7 \sigma(99.3 \%$ coverage if the data have a normal distribution); and the black dots represent the averages. The maximum concentrations and the number of measurements $(N)$ are presented at the top.

The RMSE differences between the modelled and measured $\mathrm{NO}_{2}$ concentrations (Fig. 10a.i, b.i and c.i) indicated that the linear combination between most of the global force factors, i.e. IOD, TSI, QBO and ENSO, resulted in the largest decrease in RMSE when only global force factors were included. The RIW\% listed in Table 2 for the optimum MLR equation, including only global factors, indicates that IOD ( $65.3 \%$ and $49.4 \%$, respectively) was the most significant parameter at AF and SK, while TSI (52.4\%) was the most important factor at LT. The inclusion of local, regional and global factors in the MLR model indicated that the interdependencies between $P$, IOD, QBO, ENSO and $T$ at AF; $P$, RH, IOD, ENSO and $T$ at LT; and $P, \mathrm{RH}, \mathrm{IOD}$ and ENSO at SK yielded the largest decrease in RMSE difference. The RIW\% determined for each independent variable in the optimum MLR equation containing all parameters indicated the most important factors explaining variances in the dependent variable (i.e. $\mathrm{NO}_{2}$ levels) were $P(53.7 \%)$ and IOD $(17.8 \%)$ at AF; $P(29.9 \%), \mathrm{RH}(16.6 \%)$ and IOD $(15.5 \%)$ at LT; and $P(29.8 \%)$ and $\mathrm{RH}(20.6 \%)$ at SK. It is evident from these interdependencies of the dependent variable and RIW\% of parameters included in the MLR model that local and regional factors were more significant to $\mathrm{NO}_{2}$ variability at AF, LT and SK, while global meteorological factors also contributed to variances in $\mathrm{NO}_{2}$ levels.

Population growth made the most significant contribution to modelled $\mathrm{NO}_{2}$ concentrations at all three sites and not only at $\mathrm{AF}$, as observed for $\mathrm{SO}_{2}$. Therefore, the influence of increased population growth and associated anthropogenic activities is reflected in ambient $\mathrm{NO}_{2}$ concentrations modelled for the entire north-eastern interior region. Therefore, the periods coinciding with decreased (up until 2002) and increased (2003 to 2007) $\mathrm{NO}_{2}$ inter-annual variability can be attributed to similar variances in source contribution, as discussed above for $\mathrm{SO}_{2}$, with regional circulation of air masses passing over major sources also influencing LT and SK (Fig. 2). However, the significant contribution of population growth to the modelled $\mathrm{NO}_{2}$ levels at two rural background sites (LT and SK) also points to increased household combustion associated with enlarged populations within ru- 


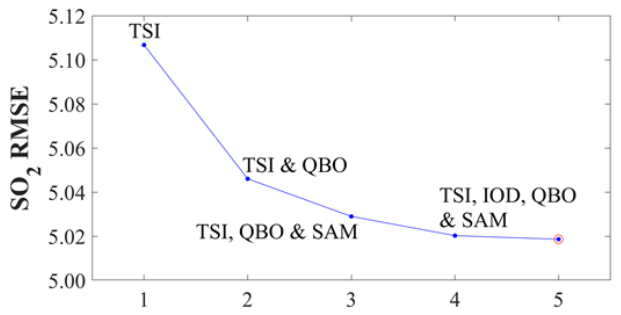

(i)

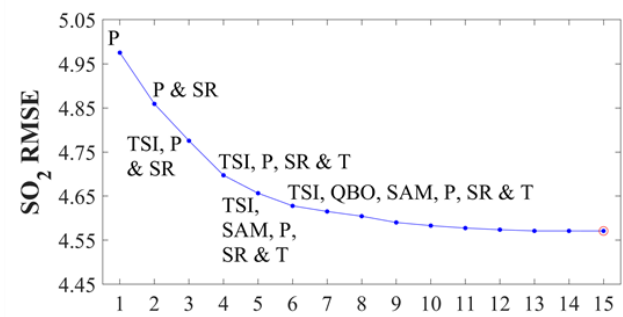

(ii)

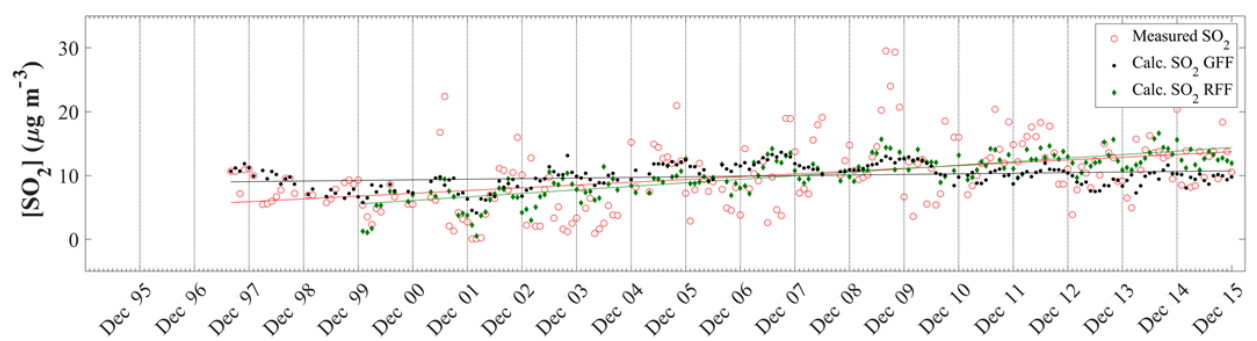

(iii)

(a)

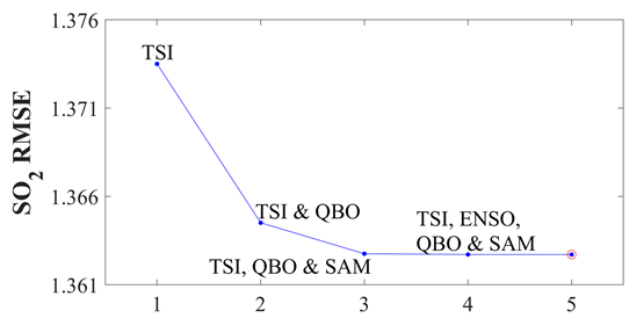

(i)

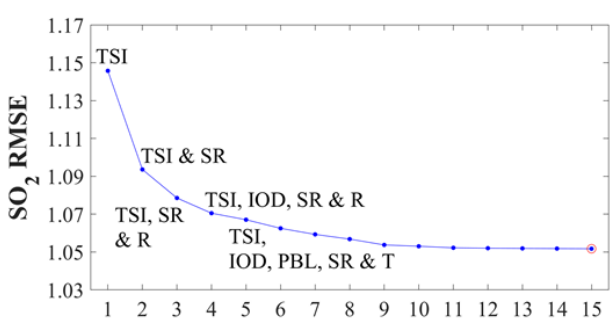

(ii)

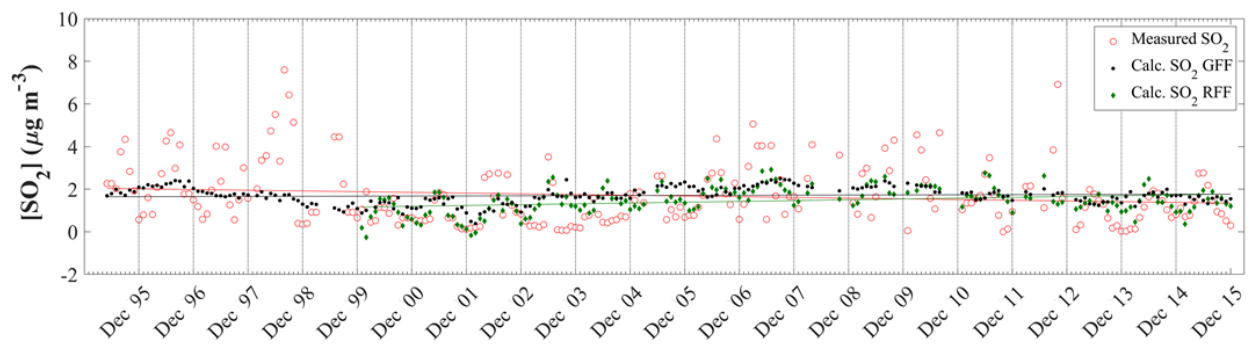

(iii)

(b)

Figure 9.

ral communities being a major source of $\mathrm{NO}_{2}$ in this part of South Africa. The influence of increased seasonal household combustion is also indicated by higher $\mathrm{NO}_{2}$ concentrations determined in June and July at SK (Fig. 4), which also signifies the impacts of the growing rural communities in proximity of SK.

RH made the second most important contribution in explaining variances in modelled $\mathrm{NO}_{2}$ concentrations at $\mathrm{LT}$ and $\mathrm{SK}$, while it was the third most important factor at AF as indicated by RIW\%. Therefore, RH can be considered the factor representing the influence of changes in local and regional meteorology at these sites. Although $T$ was indicated as a factor included in the linear combination of parameters yielding the largest decrease in RMSE at AF and SK, its relative importance in explaining modelled variances is not indicated by its RIW\% in Table 2 . The strong negative correlation with $\mathrm{RH}$ is indicative of increased $\mathrm{NO}_{2}$ corresponding with months (or years) when dry meteorological condi- 


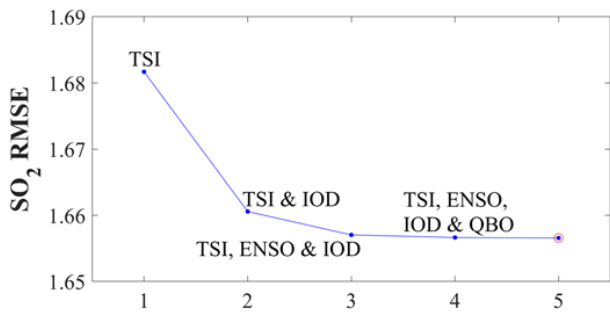

(i)

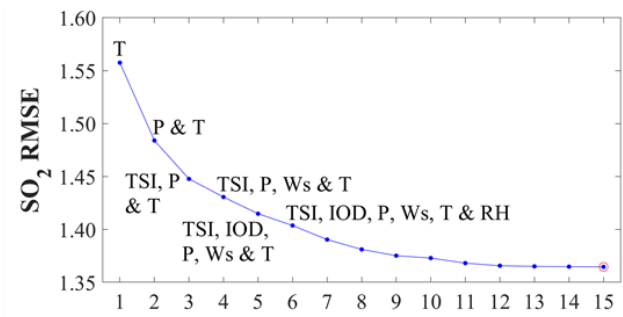

(ii)

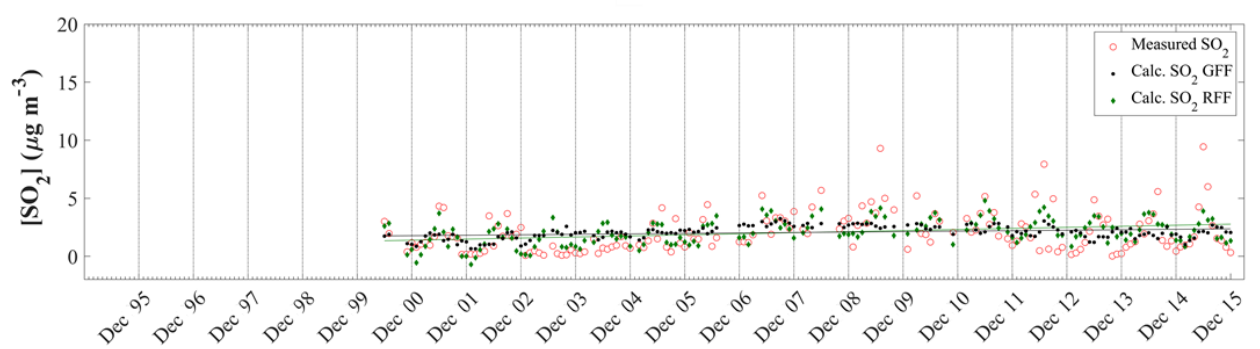

(iii)

(c)

Figure 9. (i, ii) RMSE differences between modelled and measured $\mathrm{SO}_{2}$ concentrations as a function of the number of independent variables included in the model, as well as a comparison between modelled and measured $\mathrm{SO}_{2}$ levels (iii) for global force factors only (GFF) and for global, regional and local factors (RFF) determined for AF (a), LT (b) and SK (c).

Table 1. Regression coefficients $(b)$ and relative-importance weight percentage (RIW\%) of each independent variable included in the MLR model to calculate $\mathrm{SO}_{2}$ concentrations at $\mathrm{AF}, \mathrm{LT}$ and SK.

\begin{tabular}{|c|c|c|c|c|c|c|c|c|}
\hline \multicolumn{3}{|c|}{$\mathrm{AF}$} & \multicolumn{3}{|c|}{ LT } & \multicolumn{3}{|c|}{ SK } \\
\hline & $b$ & RIW\% & & $b$ & RIW\% & & $b$ & RIW\% \\
\hline \multicolumn{9}{|c|}{ (i) Global forcing factors } \\
\hline TSI & -3.563 & 66.2 & TSI & -0.875 & 80.2 & TSI & -0.988 & 61.6 \\
\hline QBO & -0.057 & 21.2 & QBO & -0.011 & 15.2 & IOD & 1.183 & 33.8 \\
\hline IOD & 0.818 & 5.5 & SAM & -0.042 & 3.9 & ENSO & -0.158 & 3.7 \\
\hline SAM & -0.209 & 5.0 & IOD & -0.011 & 0.5 & QBO & $-2.500 \times 10^{-3}$ & 0.7 \\
\hline ENSO & 0.170 & 2.0 & ENSO & -0.012 & 0.2 & SAM & -0.010 & 0.3 \\
\hline \multicolumn{9}{|c|}{ (ii) Global, regional and local factors } \\
\hline$P$ & $1.927 \times 10^{-3}$ & 54.5 & TSI & -0.827 & 34.7 & $T$ & -0.281 & 15.9 \\
\hline TSI & -2.373 & 14.6 & SR & 0.069 & 11.3 & TSI & -0.820 & 12.0 \\
\hline SR & 0.189 & 6.2 & $T$ & -0.109 & 9.9 & SR & 0.076 & 9.9 \\
\hline$T$ & -0.588 & 4.5 & IOD & 0.588 & 8.0 & $P$ & $5.610 \times 10^{-6}$ & 9.1 \\
\hline QBO & -0.034 & 4.4 & $R$ & $6.448 \times 10^{-4}$ & 6.7 & $W_{\mathrm{s}}$ & -1.357 & 9.1 \\
\hline RH & 0.043 & 3.9 & RH & -0.014 & 6.2 & PBL & $3.134 \times 10^{-3}$ & 8.4 \\
\hline PBL & $6.396 \times 10^{-3}$ & 2.8 & $W_{\mathrm{s}}$ & -0.404 & 5.1 & $R$ & $9.233 \times 10^{-4}$ & 7.4 \\
\hline SAM & -0.406 & 2.6 & PBL & $1.520 \times 10^{-3}$ & 4.9 & RH & -0.024 & 7.0 \\
\hline$R$ & $-1.104 \times 10^{-3}$ & 1.8 & $W_{\mathrm{d}}$ & $2.746 \times 10^{-3}$ & 3.1 & IOD & 1.011 & 6.7 \\
\hline$W_{\mathrm{s}}$ & 0.076 & 1.5 & $P$ & $-1.035 \times 10^{-6}$ & 2.7 & $W_{\mathrm{d}}$ & $-4.034 \times 10^{-4}$ & 5.6 \\
\hline IOD & -0.674 & 0.9 & SAM & -0.049 & 2.4 & LFE & $5.827 \times 10^{-5}$ & 4.5 \\
\hline LFE & $1.114 \times 10^{-4}$ & 0.9 & DFE & $-2.892 \times 10^{-7}$ & 2.0 & DFE & $-3.355 \times 10^{-6}$ & 2.2 \\
\hline$W_{\mathrm{d}}$ & $-3.502 \times 10^{-3}$ & 0.6 & QBO & $-6.471 \times 10^{-3}$ & 1.6 & ENSO & -0.260 & 1.7 \\
\hline DFE & $-1.319 \times 10^{-5}$ & 0.5 & LFE & $-8.706 \times 10^{-5}$ & 0.8 & SAM & -0.078 & 0.5 \\
\hline ENSO & -0.310 & 0.3 & ENSO & -0.034 & 0.6 & QBO & $-2.726 \times 10^{-3}$ & 0.2 \\
\hline
\end{tabular}




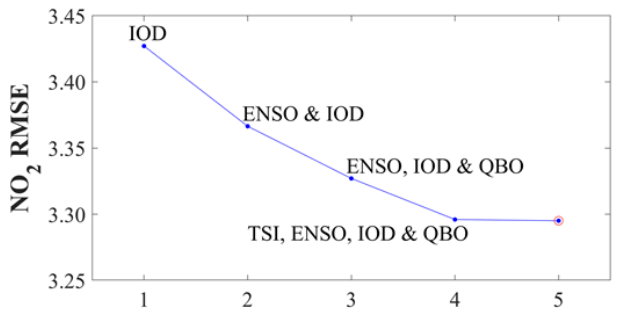

(i)

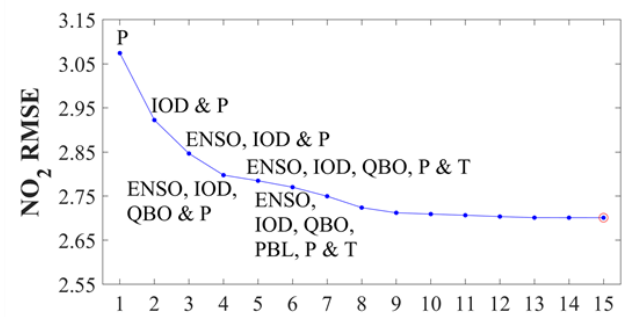

(ii)

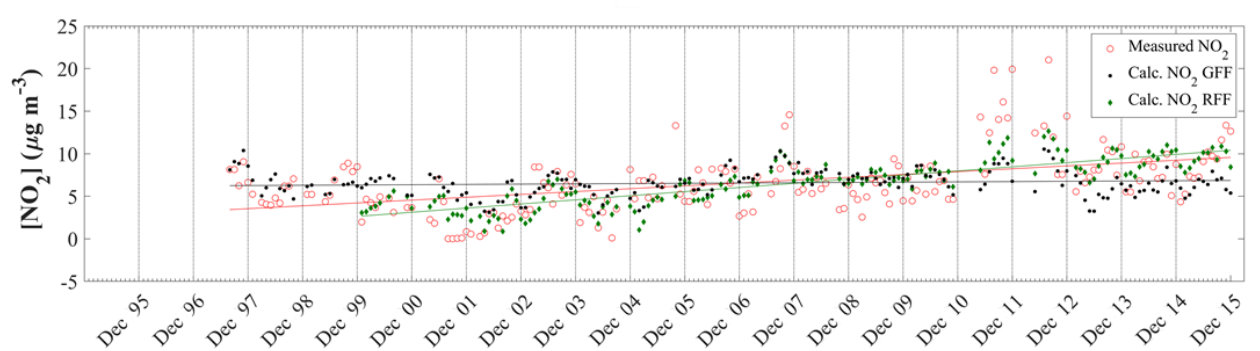

(iii)

(a)

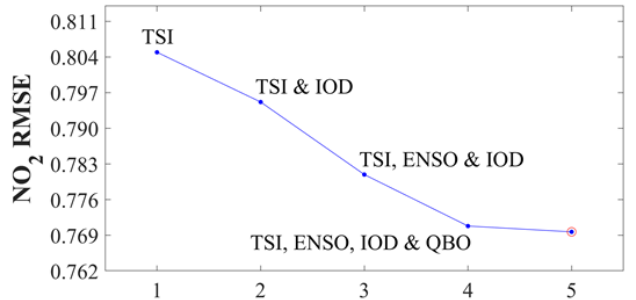

(i)

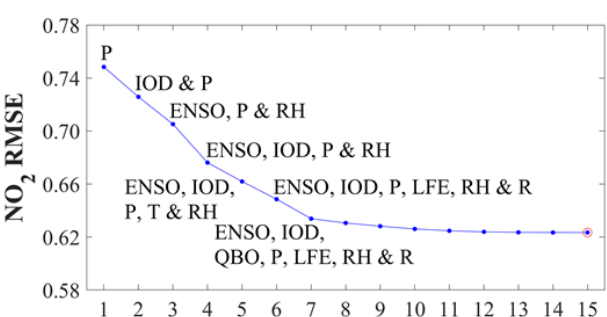

(ii)

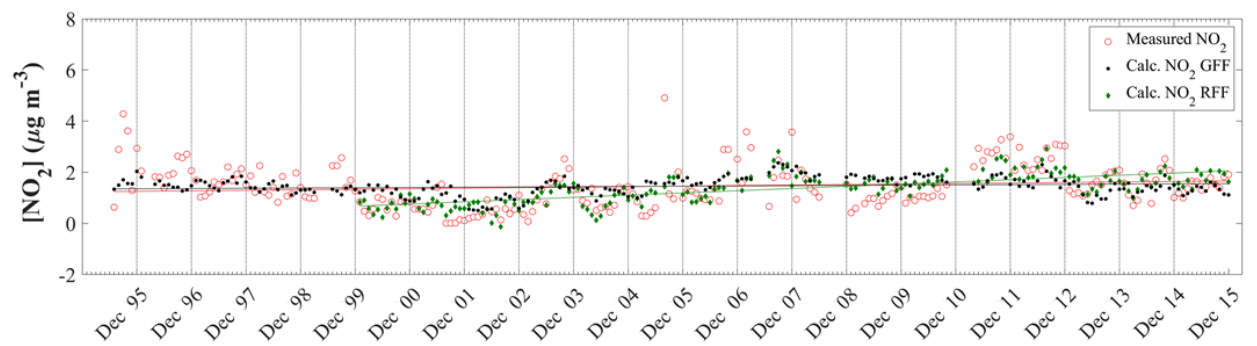

(iii)

(b)

Figure 10.

tions prevail, i.e. winter and early spring months in the northeastern interior of South Africa. As indicated in Fig. 4, higher $\mathrm{NO}_{2}$ concentrations did correspond with dry months (August to November) associated with increased biomass burning. However, the model does not reflect significant contributions of the two parameters included in the model to represent biomass burning, i.e. LFE and DFE to $\mathrm{NO}_{2}$ variability with relatively higher RIW\% observed for DFE (6.9\%) and LFE $(4.1 \%)$ only at SK. Furthermore, higher annual average $\mathrm{NO}_{2}$ concentrations observed in 2011 and 2012 (Fig. 7) at all the sites are also not explained by the MLR model.

\subsubsection{Ozone $\left(\mathrm{O}_{3}\right)$}

Modelled and measured $\mathrm{O}_{3}$ concentrations at AF, LT and SK are presented in Fig. 11, while Table 3 presents the coefficients and the RIW\% of independent variables considered in the optimum MLR equation. When only global factors are 


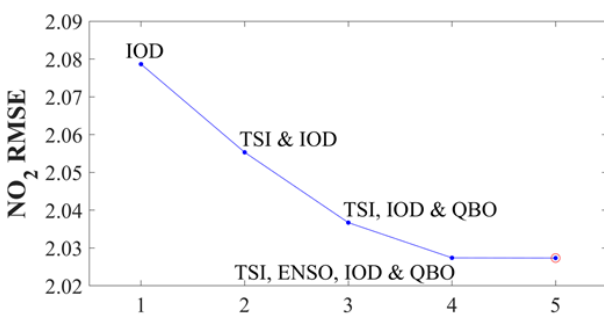

(i)

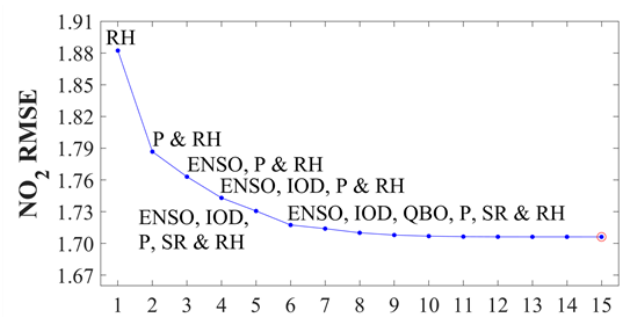

(ii)

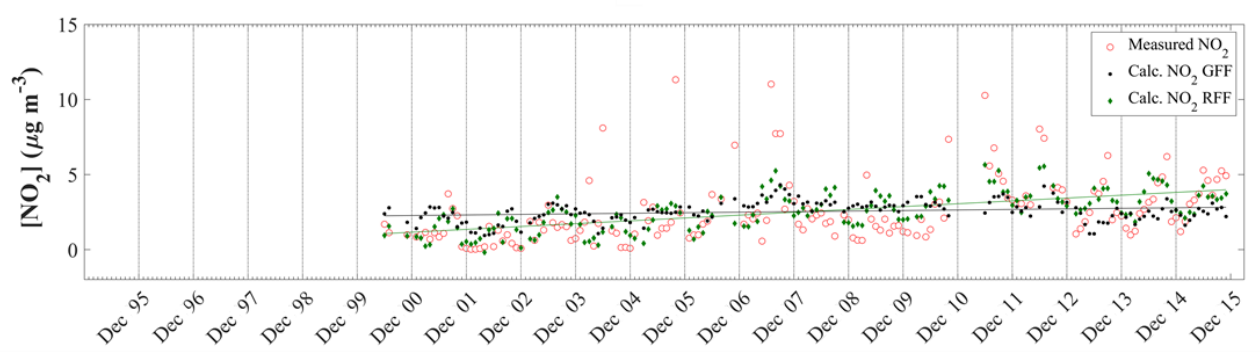

(iii)

(c)

Figure 10. (i, ii) RMSE differences between modelled and measured $\mathrm{NO}_{2}$ concentrations as a function of the number of independent variables included in the model, as well as a comparison between modelled and measured $\mathrm{NO}_{2}$ levels (iii) for global force factors only (GFF) and for global, regional and local factors (RFF) determined for AF (a), LT (b) and SK (c).

Table 2. Regression coefficients $(b)$ and relative-importance weight percentage (RIW\%) of each independent variable included in the MLR model to calculate $\mathrm{NO}_{2}$ concentrations at AF, LT and SK.

\begin{tabular}{|c|c|c|c|c|c|c|c|c|}
\hline \multicolumn{3}{|c|}{$\mathrm{AF}$} & \multicolumn{3}{|c|}{ LT } & \multicolumn{3}{|c|}{ SK } \\
\hline & $b$ & RIW\% & & $b$ & RIW\% & & $b$ & RIW\% \\
\hline \multicolumn{9}{|c|}{ (i) Global forcing factors } \\
\hline IOD & 4.718 & 65.3 & TSI & -0.625 & 52.4 & IOD & 1.954 & 49.4 \\
\hline TSI & -1.156 & 15.1 & IOD & 0.723 & 25.5 & TSI & -0.698 & 27.6 \\
\hline QBO & -0.037 & 10.5 & QBO & $-9.326 \times 10^{-3}$ & 11.8 & QBO & -0.018 & 15.4 \\
\hline ENSO & -0.798 & 8.6 & ENSO & -0.186 & 8.9 & ENSO & -0.301 & 7.1 \\
\hline SAM & 0.047 & 0.5 & SAM & 0.025 & 1.4 & SAM & $-8.422 \times 10^{-3}$ & 0.5 \\
\hline \multicolumn{9}{|c|}{ (ii) Global, regional and local factors } \\
\hline$P$ & $1.444 \times 10^{-3}$ & 53.7 & $P$ & $1.512 \times 10^{-5}$ & 29.9 & $P$ & $1.366 \times 10^{-5}$ & 29.8 \\
\hline IOD & 3.861 & 17.8 & RH & -0.056 & 16.6 & RH & -0.090 & 20.6 \\
\hline RH & -0.036 & 6.0 & IOD & 0.916 & 15.2 & IOD & 1.032 & 7.1 \\
\hline QBO & -0.028 & 3.5 & TSI & -0.186 & 8.4 & DFE & $1.473 \times 10^{-7}$ & 6.9 \\
\hline PBL & $5.119 \times 10^{-3}$ & 3.2 & ENSO & -0.327 & 6.8 & $R$ & $3.833 \times 10^{-3}$ & 6.1 \\
\hline TSI & 0.040 & 2.8 & QBO & $-9.368 \times 10^{-3}$ & 6.5 & LFE & $3.800 \times 10^{-6}$ & 4.1 \\
\hline ENSO & -0.965 & 2.7 & $R$ & $2.482 \times 10^{-3}$ & 3.8 & SR & 0.073 & 4.0 \\
\hline$W_{\mathrm{s}}$ & 0.075 & 2.7 & DFE & $-6.055 \times 10^{-7}$ & 2.9 & $T$ & -0.072 & 3.8 \\
\hline$T$ & -0.415 & 2.5 & PBL & $-1.225 \times 10^{-3}$ & 2.5 & TSI & -0.160 & 3.7 \\
\hline$R$ & 0.014 & 1.5 & $T$ & 0.069 & 1.9 & QBO & -0.015 & 3.6 \\
\hline LFE & $-1.229 \times 10^{-4}$ & 1.0 & LFE & $-2.134 \times 10^{-4}$ & 1.8 & ENSO & -0.441 & 3.1 \\
\hline DFE & $-5.044 \times 10^{-6}$ & 0.9 & $W_{\mathrm{s}}$ & 0.107 & 1.5 & $W_{\mathrm{s}}$ & 0.313 & 3.0 \\
\hline SR & 0.028 & 0.6 & SAM & 0.021 & 0.8 & $W_{\mathrm{d}}$ & $4.912 \times 10^{-4}$ & 1.9 \\
\hline$W_{\mathrm{d}}$ & $-1.419 \times 10^{-3}$ & 0.6 & SR & 0.010 & 0.8 & PBL & $1.567 \times 10^{-4}$ & 1.8 \\
\hline SAM & -0.141 & 0.5 & $W_{\mathrm{d}}$ & $-1.587 \times 10^{-4}$ & 0.6 & SAM & -0.025 & 0.5 \\
\hline
\end{tabular}


considered in the model, the linear combinations between ENSO, TSI, IOD and SAM at AF; ENSO, TSI and SAM at LT; and ENSO and IOD at SK resulted in the largest RMSE differences between measured and modelled $\mathrm{O}_{3}$ levels. However, according to RIW\% values calculated, the most significant global factor contributing to $\mathrm{O}_{3}$ variability was ENSO at all three sites $(84.1 \%, 41.8 \%$ and $96.7 \%$ at AF, LT and $\mathrm{SK}$, respectively). The interdependencies between parameters when local, regional and global factors were included in the models, as well as the RIW\% contributions of all factors included in the optimum MLR equation, also indicated the significance of ENSO in explaining variances in atmospheric $\mathrm{O}_{3}$ concentrations at all three sites. Interdependencies between ENSO, IOD, PBL, LFE and $R$ at AF; ENSO, PBL, $T, \mathrm{RH}$ and $R$ at LT; and ENSO, PBL, $T, \mathrm{RH}$ and $R$ at SK yielded the largest decrease in RMSE differences between measured and modelled $\mathrm{O}_{3}$ levels, while RIW\% indicated that the largest contributions made by factors explaining $\mathrm{O}_{3}$ variability were ENSO $(22.6 \%), R(14.6 \%)$ and $W_{\mathrm{s}}$ $(10.1 \%)$ at AF; RH (23.1\%), ENSO (16.8\%) and $T(10.5 \%)$ at LT; and $T(24.6 \%)$, ENSO (19.5\%), RH (11.3\%) and DFE $(10.1 \%)$ at SK when local, regional and global factors were included in the model.

The significant contribution of ENSO on variances of the dependent variable (modelled $\mathrm{O}_{3}$ concentrations) is evident at all three sites, with RIW\% indicating ENSO to be the major factor at $\mathrm{AF}$ and the second most important factor at LT and SK when local, regional and meteorological factors are included in the model. Therefore, inter-annual variability in $\mathrm{O}_{3}$ concentrations can most likely be attributed to ENSO cycles. El Niño periods are associated with drier and warmer conditions in the South African interior, which are conducive to $\mathrm{O}_{3}$ formation, while cloudy and increased rainfall conditions related to La Niña hinder $\mathrm{O}_{3}$ production (Balashov et al., 2014). Balashov et al. (2014) indicated that surface $\mathrm{O}_{3}$ concentrations on the South African Highveld are sensitive to ENSO, with the El Niño period amplifying $\mathrm{O}_{3}$ formation. The influence of local and regional meteorological conditions is also indicated by the substantial contributions of $R$ and $W_{\mathrm{S}}$ at AF, as well as $T$ and RH at LT and SK on modelled $\mathrm{O}_{3}$ levels. At LT, $\mathrm{RH}$ made the most substantial contribution to the dependent variable, while $T$ made the most significant contribution to modelled $\mathrm{O}_{3}$ levels. The negative correlation to $T$ and $\mathrm{RH}$ at LT and $\mathrm{SK}$ is indicative of higher $\mathrm{O}_{3}$ concentrations corresponding with drier colder months, as indicated in Fig. 5. Laban et al. (2018) indicated the significance of $\mathrm{RH}$ to surface $\mathrm{O}_{3}$ concentrations in the north-eastern part of South Africa through the statistical analysis of in situ $\mathrm{O}_{3}$ measurements conducted in this region, with $\mathrm{RH}$ also negatively correlated to surface $\mathrm{O}_{3}$ levels. The positive correlation to $R$ and $W_{\mathrm{s}}$ at $\mathrm{AF}$ reflects higher $\mathrm{O}_{3}$ concentrations measured during late spring and summer at AF, i.e. October to January, which is a period associated with increased rainfall and less stable meteorological conditions (Fig. 5). The influence of regional open biomass burning during late winter and spring (August to November) on surface $\mathrm{O}_{3}$ concentrations in this part of South Africa is indicated by the relatively significant contribution of DFE on modelled $\mathrm{O}_{3}$ concentrations at LT and SK. A recent paper reporting tropospheric $\mathrm{O}_{3}$ levels measured at four sites in the north-eastern interior of South Africa indicated that $\mathrm{O}_{3}$ is a regional problem, with $\mathrm{O}_{3}$ concentration measured at these four sites being similar to levels thereof measured at AF, LT and SK (Laban et al., 2018). A time series of $\mathrm{O}_{3}$ levels measured from 2010 to 2015 at one of the sites presented by Laban et al. (2018) also indicated higher $\mathrm{O}_{3}$ concentration corresponding to drier years associated with the ENSO cycle.

As indicated in Fig. 8, inter-annual $\mathrm{O}_{3}$ concentrations at LT decreased from 1995 to 2001, which corresponded to the period when $\mathrm{SO}_{2}$ and $\mathrm{NO}_{2}$ concentrations decreased, as discussed in Sect. 3.1. This period of inter-annual decrease in $\mathrm{O}_{3}$ levels is not reflected in the statistical model. Since LT is a rural background site with low $\mathrm{NO}_{x}$ emissions, it can be considered to be located in an $\mathrm{NO}_{x}$-limited $\mathrm{O}_{3}$ production regime, where $\mathrm{O}_{3}$ concentrations correspond with $\mathrm{NO}_{x}$ concentrations, i.e. an increase or decrease with increasing or decreasing $\mathrm{NO}_{x}$. Therefore, the decrease in $\mathrm{O}_{3}$ concentrations from 1995 to 2001 can be attributed to decreasing $\mathrm{NO}_{2}$ concentrations during this period and the factors influencing $\mathrm{NO}_{2}$ concentrations at LT, i.e. mainly population growth, as discussed above (Sect. 3.2.2).

The comparisons between modelled and measured $\mathrm{O}_{3}$ concentrations (Fig. 11a.iii, b.iii and c.iii) also indicated, as observed for $\mathrm{SO}_{2}$ and $\mathrm{NO}_{2}$, that the correlations are significantly improved when local, regional and global factors are included in the model. The $R^{2}$ values, when only global factors are included, i.e. 0.042, 0.048 and 0.094 at AF, LT and SK, respectively, are improved to $0.259,0.241$ and 0.389 at AF, LT and SK, respectively. These correlations can be considered relatively weak, with the exception of a moderate correlation at SK (Sheskin, 2003). These generally weaker correlations can be attributed to the complexity associated with tropospheric $\mathrm{O}_{3}$ chemistry. Tropospheric $\mathrm{O}_{3}$ is a secondary atmospheric pollutant with several factors contributing to its variability. In addition, Laban et al. (2018) indicated the significance of the precursor species $\mathrm{CO}$ to surface $\mathrm{O}_{3}$ concentrations in the north-eastern interior of South Africa, which were not measured at any of the sites and included in the model. Swartz et al. (2020) also compared passively derived $\mathrm{O}_{3}$ concentrations with active $\mathrm{O}_{3}$ measurements and illustrated limitations associated with the use of passive samplers to determine $\mathrm{O}_{3}$ concentrations. However, the general trend of measured $\mathrm{O}_{3}$ concentrations is mimicked by the modelled $\mathrm{O}_{3}$ values when local, regional and global factors are included in the model, while the overall trend is weakly followed when only global factors are included. Higher and lower $\mathrm{O}_{3}$ concentrations are underestimated by the MLR model.

The trend lines for the $\mathrm{O}_{3}$ concentrations measured during the entire sampling periods indicate slight negative slopes at 


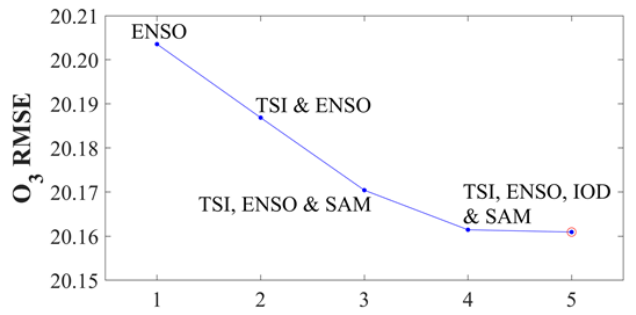

(i)

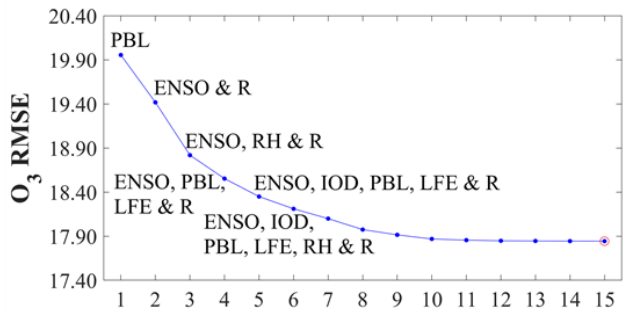

(ii)

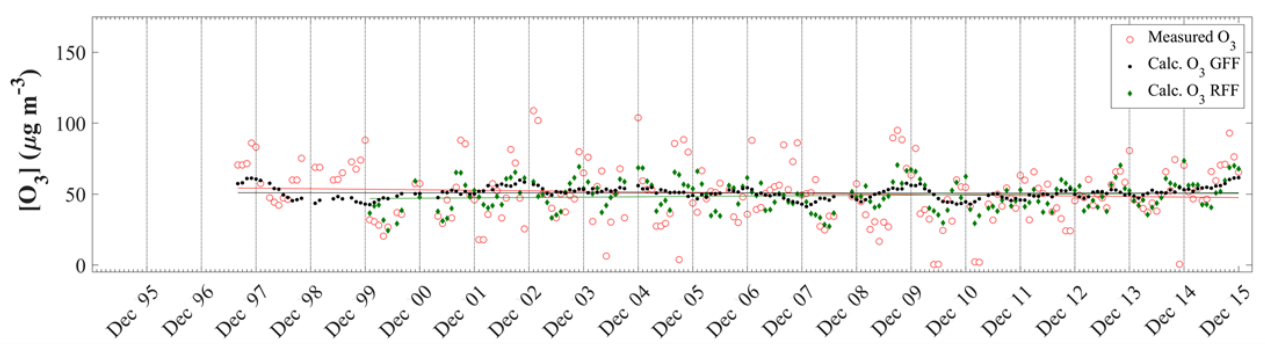

(iii)

(a)

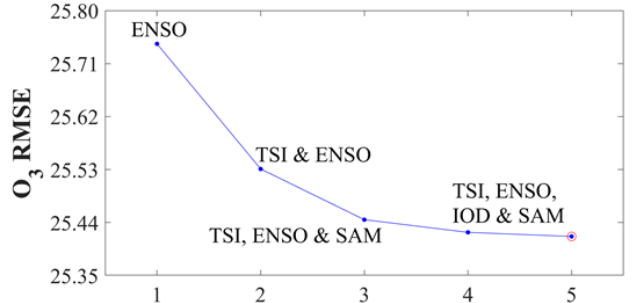

(i)

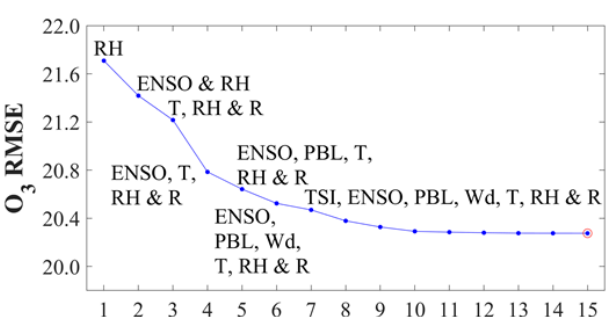

(ii)

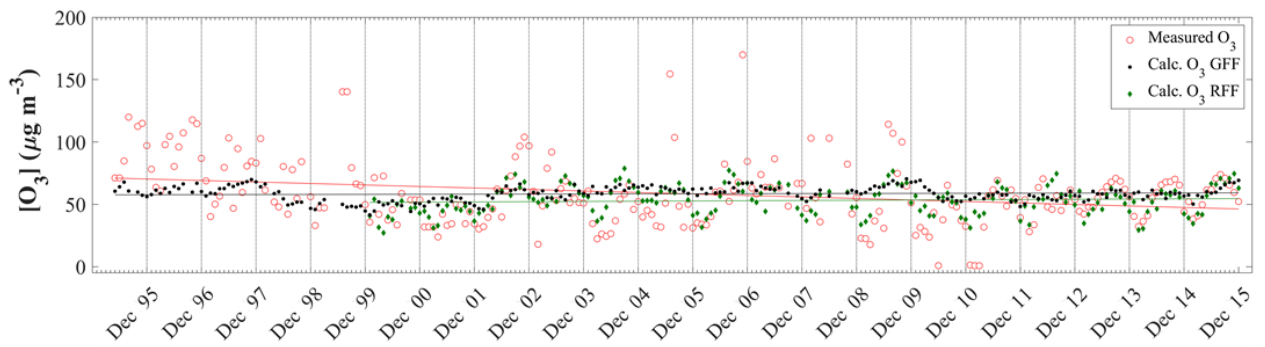

(iii)

(b)

Figure 11.

AF and LT (Fig. 11a.iii and b.iii, respectively) and a small positive slope at SK (Fig. 11c.iii). Annual average decreases in $\mathrm{O}_{3}$ levels of 0.37 and $1.20 \mu \mathrm{g} \mathrm{m}^{-3} \mathrm{yr}^{-1}$ were calculated at $\mathrm{AF}$ and LT, respectively, while an average annual increase of $0.21 \mu \mathrm{g} \mathrm{m}^{-3} \mathrm{yr}^{-1}$ was calculated at SK. However, in general, it seems that $\mathrm{O}_{3}$ concentrations remained relatively constant at all three sites for the entire 19-, 21- and 16-year sampling periods at AF, LT and SK, respectively. Decadal trends of -3.46 (average $\mathrm{O}_{3}$ concentrations from 1997 to 2006 were $52.56 \mathrm{\mu g} \mathrm{m}^{-3}$, and average $\mathrm{O}_{3}$ concentrations from 2007 to 2015 were $49.10 \mu \mathrm{g} \mathrm{m}^{-3}$ ) and $-9.15 \mu \mathrm{g} \mathrm{m}^{-3}$ per decade (average $\mathrm{O}_{3}$ concentrations from 1995 to 2004 were $63.16 \mu \mathrm{g} \mathrm{m}^{-3}$, and average $\mathrm{O}_{3}$ concentrations from 2005 to 2014 were $53.01 \mathrm{\mu g} \mathrm{m}^{-3}$ ) were calculated for AF and LT, respectively, for the 2 decades. Similar to $\mathrm{SO}_{2}$ and $\mathrm{NO}_{2}$, the slopes of the linear regression trend lines for the measured and modelled $\mathrm{O}_{3}$ concentrations when local, regional and global factors are included are exactly the same at AF, LT and 


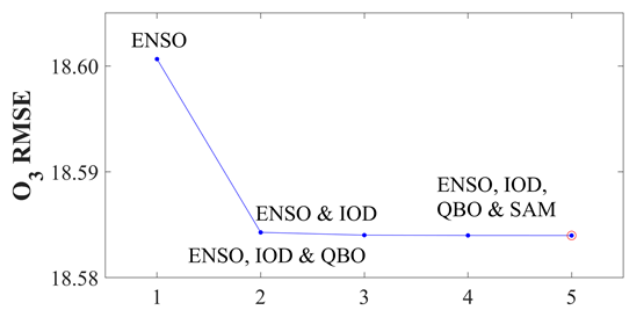

(i)

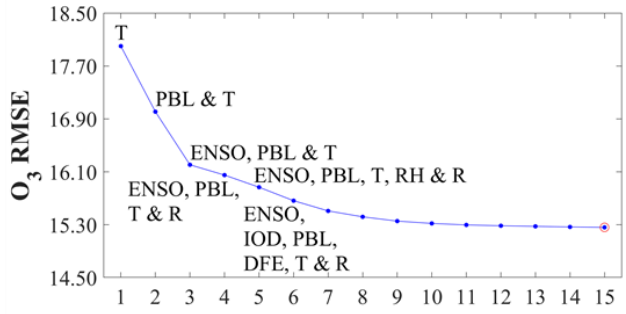

(ii)

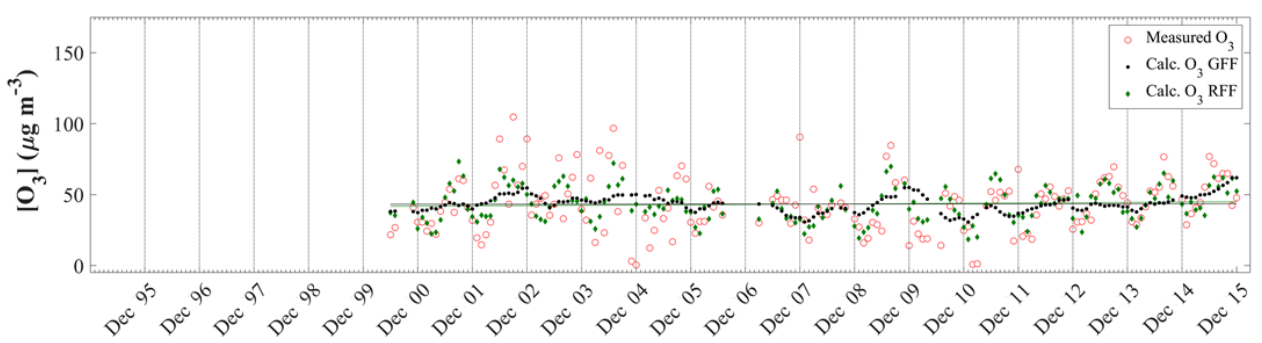

(iii)

(c)

Figure 11. (i, ii) RMSE differences between modelled and measured $\mathrm{O}_{3}$ concentrations as a function of the number of independent variables included in the model, as well as a comparison between modelled and measured $\mathrm{O}_{3}$ levels (iii) for global force factors only (GFF) and for global, regional and local factors (RFF) determined for AF (a), LT (b) and SK (c).

SK (Fig. 11a.iii, b.iii and c.iii), which indicates that measured and modelled $\mathrm{O}_{3}$ trends compare well in spite of low $R^{2}$ values. In addition, relatively good correlations are observed between the slopes of the trend lines of measured $\mathrm{O}_{3}$ concentrations and modelled $\mathrm{O}_{3}$ values calculated when only global factors are included at all the sites, signifying the influence of global factors, especially ENSO, as indicated above, on $\mathrm{O}_{3}$ variability (Fig. 11a.iii, b.iii and c.iii).

\subsection{Contextualization}

In order to contextualize the long-term $\mathrm{SO}_{2}, \mathrm{NO}_{2}$ and $\mathrm{O}_{3}$ concentrations measured with passive samplers at $\mathrm{AF}, \mathrm{LT}$ and SK located in the north-eastern interior of South Africa, the statistical spread of the concentrations of these species determined during the entire sampling period at each site are compared to average concentrations of these species determined with passive samplers during other studies in South Africa and Africa, as well as regional sites in other parts of the world. $\mathrm{SO}_{2}, \mathrm{NO}_{2}$ and $\mathrm{O}_{3}$ concentrations determined in this study are related to levels reported elsewhere in Figs. 12, 13 and 14 , respectively.

As expected, the average and median $\mathrm{SO}_{2}$ concentrations determined at the industrially impacted AF (9.91 and $9.48 \mu \mathrm{g} \mathrm{m}^{-3}$, respectively) site were higher compared to average and median $\mathrm{SO}_{2}$ levels determined at the rural background sites LT ( 1.70 and $1.35 \mu \mathrm{g} \mathrm{m}^{-3}$, respectively) and SK ( 2.07 and $1.60 \mu \mathrm{g} \mathrm{m}^{-3}$, respectively) for the entire sampling period at each site. Geospatial maps of $\mathrm{SO}_{2}$ column amount in the planetary boundary layer and $\mathrm{NO}_{2}$ tropospheric column density averaged over the period 2005 to 2015 over southern Africa (Figs. A5 and A6,' respectively) indicate higher average $\mathrm{SO}_{2}$ and $\mathrm{NO}_{2}$ concentrations being observed over the region where AF is located. Much lower average $\mathrm{SO}_{2}$ and $\mathrm{NO}_{2}$ concentrations are observed over the northernmost parts of the country, where LT is located, as well as the western region where SK is situated. Therefore, the influence of coal-fired power stations on $\mathrm{SO}_{2}\left(\right.$ and $\left.\mathrm{NO}_{2}\right)$ levels measured at $\mathrm{AF}$ is evident. The average $\mathrm{SO}_{2}$ levels at $\mathrm{AF}$ were similar to average $\mathrm{SO}_{2}$ concentrations determined at other sites located in the Mpumalanga Highveld, for which the measurement period was from August 2007 to July 2008 (Lourens et al., 2011). However, the average $\mathrm{SO}_{2}$ level at AF was significantly lower than the mean $\mathrm{SO}_{2}$ levels at Elandsfontein, Delmas and eMalahleni (formerly Witbank). Elandsfontein and Delmas are situated within closer proximity to major industrial activities in the Mpumalanga Highveld, while eMalahleni (Witbank) is a relatively large urban area with numerous large industrial point sources (Lourens et al., 2011). In addition, the average $\mathrm{SO}_{2}$ concentrations at Vanderbijlpark - an urban area located within the highly industrialized Vaal Triangle region - were also higher compared to levels thereof at AF. Average $\mathrm{SO}_{2}$ concentrations determined at regional sites in South America and India, i.e. Marcapomacocha and Cochin, respectively, were also similar to mean $\mathrm{SO}_{2}$ levels determined at AF (Carmichael et al., 2003). The measurement period of the Carmichael et al. (2003) study 


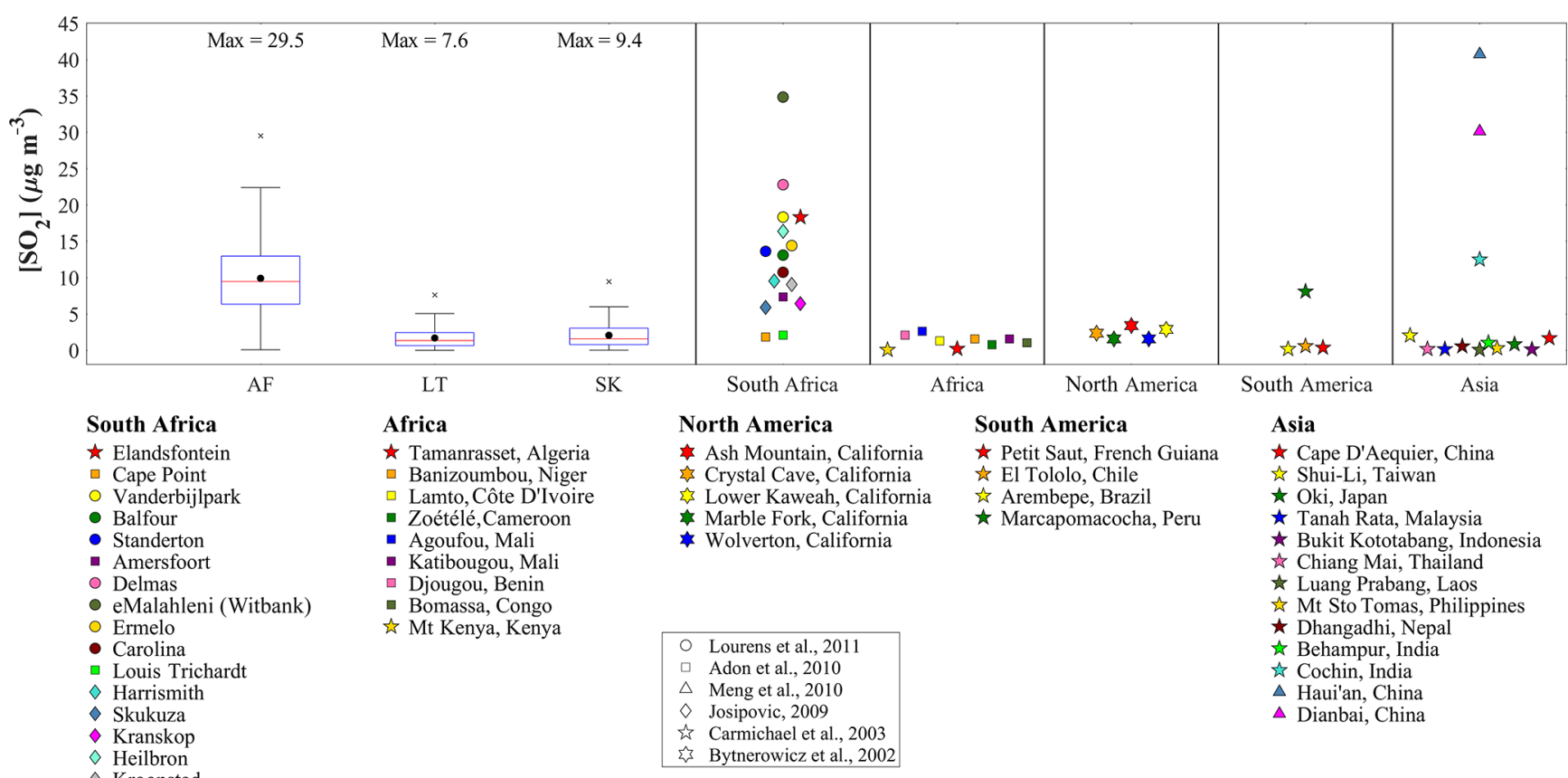

Figure 12. Statistical spread of $\mathrm{SO}_{2}$ concentrations determined during the entire measuring period at each site compared to mean levels determined with passive samplers elsewhere. The red line of each box represents the median; the top and bottom edges of the box represent the 25th and 75th percentiles, respectively; the whiskers are $\pm 2.7 \sigma$ (99.3\% coverage if the data have a normal distribution); and the black dots represent the average concentrations.

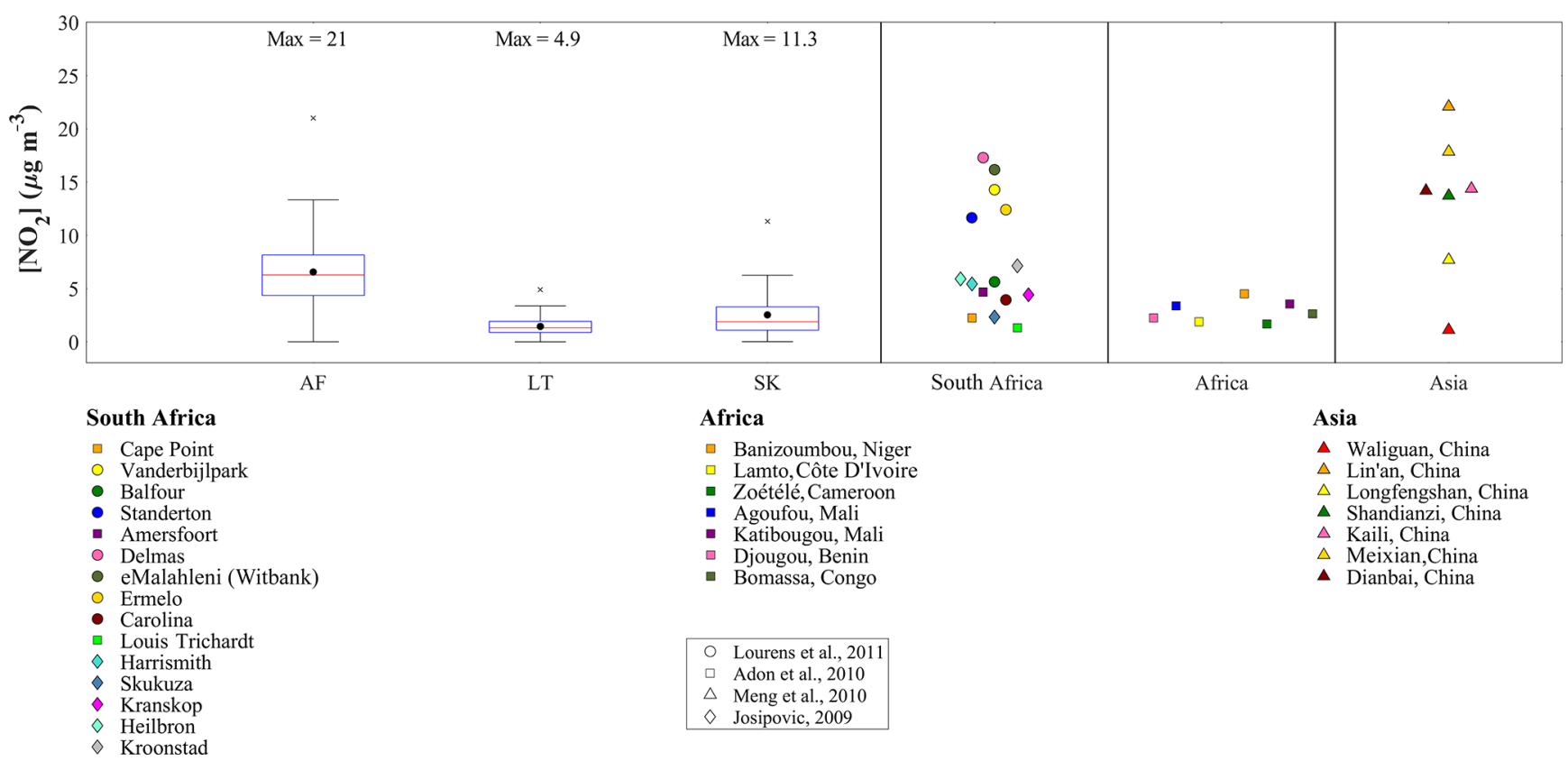

Figure 13. Statistical spread of $\mathrm{NO}_{2}$ concentrations determined during the entire measuring period at each site compared to mean levels determined with passive samplers elsewhere. The red line of each box represents the median; the top and bottom edges of the box represent the 25th and 75th percentiles, respectively; the whiskers are $\pm 2.7 \sigma(99.3 \%$ coverage if the data have a normal distribution); and the black dots represent the average concentrations. 
Table 3. Regression coefficients $(b)$ and relative-importance weight percentage (RIW\%) of each independent variable included in the MLR model to calculate $\mathrm{O}_{3}$ concentrations at AF, LT and SK.

\begin{tabular}{|c|c|c|c|c|c|c|c|c|}
\hline \multicolumn{3}{|c|}{$\mathrm{AF}$} & \multicolumn{3}{|c|}{ LT } & \multicolumn{3}{|c|}{ SK } \\
\hline & $b$ & RIW\% & & $b$ & RIW\% & & $b$ & RIW\% \\
\hline \multicolumn{9}{|c|}{ (i) Global forcing factors } \\
\hline ENSO & 4.923 & 84.1 & ENSO & 4.732 & 41.8 & ENSO & 8.353 & 96.7 \\
\hline SAM & -0.539 & 7.9 & TSI & -8.397 & 36.3 & IOD & -3.151 & 1.5 \\
\hline IOD & -2.337 & 5.2 & SAM & -1.313 & 18.0 & TSI & -0.034 & 1.5 \\
\hline TSI & 1.844 & 2.5 & IOD & -4.231 & 2.6 & SAM & -0.020 & 0.2 \\
\hline QBO & 0.010 & 0.2 & QBO & 0.044 & 1.2 & QBO & $-6.823 \times 10^{-3}$ & 0.1 \\
\hline \multicolumn{9}{|c|}{ (ii) Global, regional and local factors } \\
\hline ENSO & 7.478 & 22.6 & $\mathrm{RH}$ & -0.966 & 23.1 & $T$ & -5.378 & 24.6 \\
\hline$R$ & 0.122 & 14.6 & ENSO & 5.135 & 16.8 & ENSO & 7.458 & 19.5 \\
\hline$W_{\mathrm{s}}$ & 5.988 & 10.1 & $T$ & -3.542 & 10.5 & RH & -0.276 & 11.3 \\
\hline SR & 0.474 & 9.4 & DFE & $1.070 \times 10^{-5}$ & 9.7 & DFE & $3.886 \times 10^{-5}$ & 10.1 \\
\hline PBL & $2.287 \times 10^{-3}$ & 7.7 & PBL & 0.043 & 7.2 & PBL & 0.070 & 8.6 \\
\hline$T$ & 0.306 & 7.5 & $R$ & 0.166 & 6.5 & SR & 1.376 & 8.2 \\
\hline LFE & $9.076 \times 10^{-4}$ & 6.8 & $W_{\mathrm{d}}$ & -0.087 & 4.7 & $R$ & 0.100 & 4.3 \\
\hline$W_{\mathrm{d}}$ & -0.029 & 5.1 & SR & 0.340 & 4.5 & LFE & $-5.803 \times 10^{-4}$ & 3.7 \\
\hline RH & -0.257 & 4.7 & IOD & 4.900 & 4.4 & $W_{\mathrm{d}}$ & -0.036 & 3.3 \\
\hline DFE & $1.185 \times 10^{-5}$ & 4.2 & $W_{\mathrm{s}}$ & -0.601 & 4.2 & $W_{\mathrm{s}}$ & -2.536 & 2.8 \\
\hline IOD & -12.736 & 3.7 & TSI & -4.195 & 3.2 & IOD & -11.527 & 1.4 \\
\hline$P$ & $6.657 \times 10^{-4}$ & 1.2 & LFE & $-5.076 \times 10^{-3}$ & 2.3 & $P$ & $3.013 \times 10^{-5}$ & 1.0 \\
\hline SAM & -0.339 & 1.2 & $P$ & $-1.834 \times 10^{-4}$ & 1.5 & TSI & 1.670 & 1.0 \\
\hline TSI & -2.989 & 0.6 & SAM & 0.101 & 0.9 & QBO & 0.038 & 0.1 \\
\hline QBO & 0.018 & 0.4 & QBO & 0.031 & 0.1 & SAM & -0.279 & 0.1 \\
\hline
\end{tabular}

was 12 months, starting in September 1999 (Carmichael et al., 2003). $\mathrm{SO}_{2}$ concentrations reported for two rural sites in China, i.e. Dianbai and Haui'an, were similar to $\mathrm{SO}_{2}$ levels determined at eMalahleni (Witbank) (Meng et al., 2010). Meng et al. (2010) presented results obtained during a 2-year study that commenced in January 2007. The mean $\mathrm{SO}_{2}$ concentrations determined at LT and SK were similar to average $\mathrm{SO}_{2}$ concentrations determined at regional background sites in western and central African sites (Carmichael et al., 2003; Adon et al., 2010), as well as mean $\mathrm{SO}_{2}$ levels determined at most of the regional sites in North America - measured between May and November 1999, South America and Asia (Bytnerowicz et al., 2002; Carmichael et al., 2003). Adon et al. (2010) presented ambient $\mathrm{SO}_{2}, \mathrm{NO}_{2}$ and $\mathrm{O}_{3}$ concentrations measured from 1998 to 2007 at Katibougou in Mali, Banizoumbou in Niger, Lamto in Côte D'Ivoire and Zoétélé in Cameroon. The measurement periods for Agoufou in Mali and Djougou in Benin was from 2005 to 2007, while for Bomassa in Congo measurements were reported between 1998 and 2006 (Adon et al., 2010).

Similar to $\mathrm{SO}_{2}$, the mean and median $\mathrm{NO}_{2}$ levels determined for the respective sampling periods at each site were higher at AF (6.56 and $6.29 \mu \mathrm{g} \mathrm{m}^{-3}$, respectively) compared to mean and median levels thereof at LT (1.45 and
$1.32 \mu \mathrm{g} \mathrm{m}^{-3}$, respectively) and SK (2.54 and $1.89 \mu \mathrm{g} \mathrm{m}^{-3}$, respectively). Relatively higher $\mathrm{NO}_{2}$ concentrations were determined at SK compared to LT, which can be attributed to the influence of growing rural communities on the border of the Kruger National Park (Maritz et al., 2019). The mean $\mathrm{NO}_{2}$ concentrations at AF were lower compared to most of the average $\mathrm{NO}_{2}$ levels determined at other sites located in the Mpumalanga Highveld within closer proximity to industrial sources, while being similar to mean $\mathrm{NO}_{2}$ concentrations measured at Balfour and Carolina. In addition, average $\mathrm{NO}_{2}$ levels at AF were also lower-than-average $\mathrm{NO}_{2}$ concentrations determined in the Vaal Triangle (Lourens et al., 2011). Average $\mathrm{NO}_{2}$ concentrations determined at rural and regional sites in China were higher than mean $\mathrm{NO}_{2}$ levels at $\mathrm{AF}$, with the exception of Longfengshan that had similar $\mathrm{NO}_{2}$ concentrations to AF (Meng et al., 2010), which reflects the scale of atmospheric pollution in China. The average $\mathrm{NO}_{2}$ concentrations at LT and SK were also similar to mean $\mathrm{NO}_{2}$ levels determined at regional sites in western and central African sites (Carmichael et al., 2003; Adon et al., 2010), as well as a remote site (Waliguan) in China (Meng et al., 2010).

The statistical distribution of $\mathrm{O}_{3}$ concentrations determined at AF, LT and SK indicates similar surface $\mathrm{O}_{3}$ levels at 


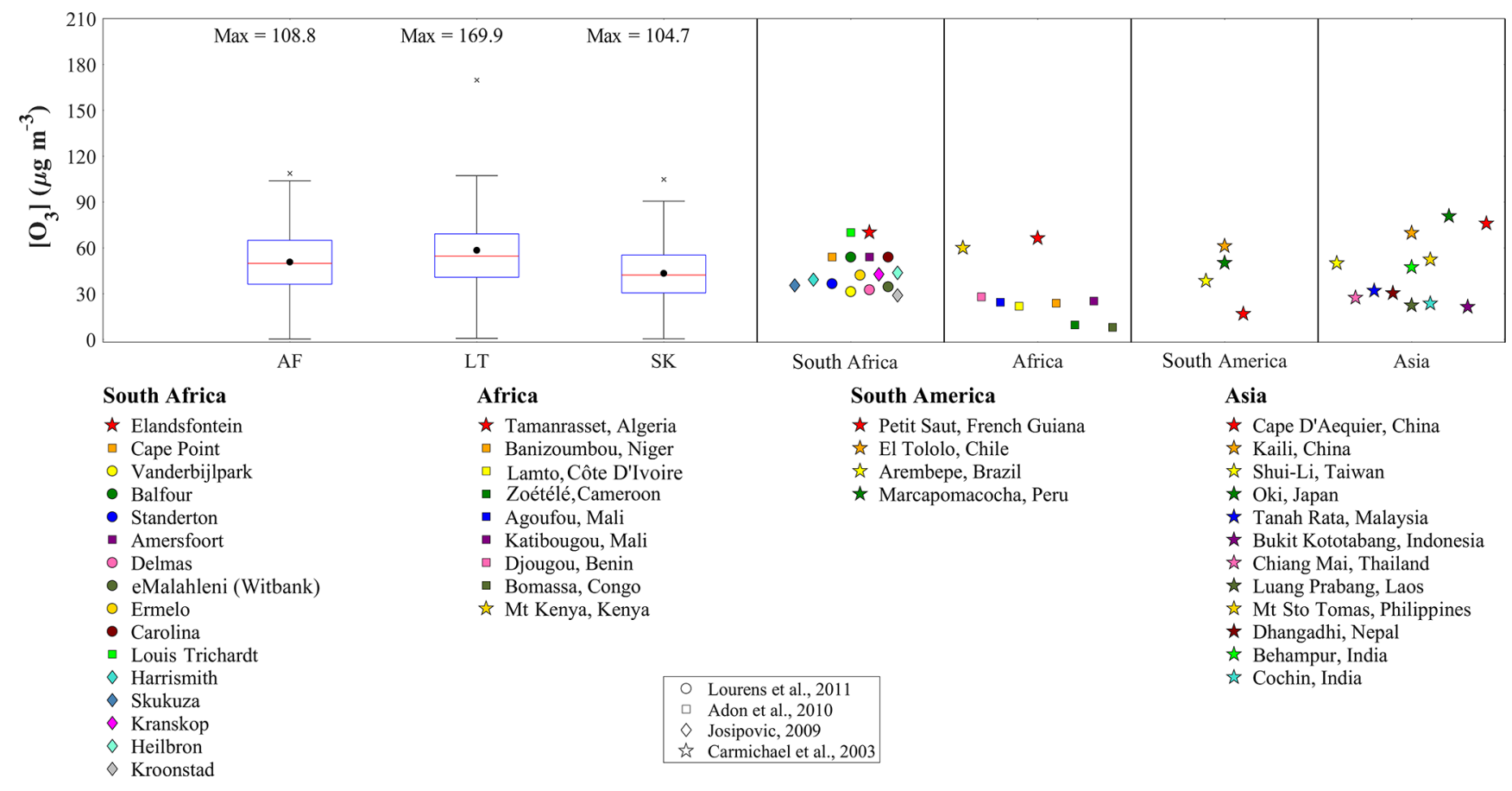

Figure 14. Statistical spread of $\mathrm{O}_{3}$ concentrations determined during the entire measuring period at each site compared to mean levels determined with passive samplers elsewhere. The red line of each box represents the median; the top and bottom edges of the box represent the 25th and 75th percentiles, respectively; the whiskers are $\pm 2.7 \sigma(99.3 \%$ coverage if the data have a normal distribution); and the black dots represent the average concentrations.

all three sites with marginally higher $\mathrm{O}_{3}$ concentrations determined at LT (58.44 and $54.67 \mu \mathrm{g} \mathrm{m}^{-3}$, respectively) compared to AF (50.77 and $49.84 \mu \mathrm{g} \mathrm{m}^{-3}$, respectively) and SK (43.36 and $42.20 \mu \mathrm{g} \mathrm{m}^{-3}$, respectively). Higher $\mathrm{O}_{3}$ levels are expected at the rural background LT site due to decreased $\mathrm{O}_{3}$ titration compared to polluted regions, while LT is also impacted by aged air masses passing over the Mpumalanga Highveld source region as previously indicated. However, the regional $\mathrm{O}_{3}$ problem in the South African interior is reflected by high $\mathrm{O}_{3}$ concentrations also measured at the industrially influenced AF site, as well as similar $\mathrm{O}_{3}$ levels determined at other sites in the Mpumalanga Highveld (Lourens et al., 2011). Laban et al. (2018) attributed high regional $\mathrm{O}_{3}$ concentrations in the north-eastern interior of South Africa to the influence of household combustion and widespread open biomass burning impacting this region. In addition, the influence of rural communities is also reflected by the slightly lower average $\mathrm{O}_{3}$ levels at $\mathrm{SK} . \mathrm{O}_{3}$ concentrations measured at western and central Africa sites were lower than South African $\mathrm{O}_{3}$ levels (Adon et al., 2010), with the exception of Mt Kenya and a site in northern Africa that had similar $\mathrm{O}_{3}$ concentrations (Carmichael et al., 2003). Similar $\mathrm{O}_{3}$ concentrations were determined at the South American regional sites, except for Petit Saut, which had lower $\mathrm{O}_{3}$ concentrations (Carmichael et al., 2003). Average $\mathrm{O}_{3}$ levels determined at some of the regional Asian sites were in the same range as $\mathrm{O}_{3}$ concentrations over the interior of South Africa, while certain sites in Asia had lower mean $\mathrm{O}_{3}$ levels (Carmichael et al., 2003).

\section{Summary and conclusions}

In this study, long-term trends of atmospheric $\mathrm{SO}_{2}, \mathrm{NO}_{2}$ and $\mathrm{O}_{3}$ concentrations measured with passive samplers at three sites located in the north-eastern interior of South Africa are presented. This paper illustrates the value of low-cost atmospheric sampling techniques in order to obtain longterm data, especially for regions restricted by logistical accessibility and limited capacity. A 19-year (1997 to 2015), 21-year (1995 to 2015) and 16-year (2000 to 2015) dataset for AF, LT and SK could be evaluated. Long-term temporal trends indicated seasonal and inter-annual variability at all three sites, which could be ascribed to changes in meteorological conditions and/or variances in source contribution. Inter-annual variability indicated periods up until 2003/2004 and 2002 during which $\mathrm{SO}_{2}$ and $\mathrm{NO}_{2}$ concentrations, respectively, decreased, followed by periods during which $\mathrm{SO}_{2}$ and $\mathrm{NO}_{2}$ levels increased up until 2009 and 2007, respectively. These long-term trends were assessed with an MLR model in order to establish the influence of sources, as well as local, regional and global meteorology on atmospheric $\mathrm{SO}_{2}, \mathrm{NO}_{2}$ and $\mathrm{O}_{3}$ concentrations. 
Interdependencies between local, regional and global parameters included in the statistical model indicated the influence of global meteorology on $\mathrm{SO}_{2}$ variability at all three sites, especially at the rural background site LT. However, population growth was the most substantial factor in the statistical model at the industrially impacted AF site, while the significance of local and regional meteorology was also evident with $T$ being the most significant factor at SK. The important contribution of population growth on modelled $\mathrm{SO}_{2}$ levels at AF was indicative of the impact of increased anthropogenic activities and energy demand in the north-eastern interior of South Africa. Higher $\mathrm{SO}_{2}$ concentrations associated with lower temperatures reflected the influence of pollution build-up during winter, while the influence of air masses passing over the source region is also evident at SK and LT. Although global parameters contributed to variances in $\mathrm{NO}_{2}$ concentrations, local and regional factors made more substantial contributions to modelled $\mathrm{NO}_{2}$ levels. The most significant factor explaining $\mathrm{NO}_{2}$ variability at all three sites was population growth, while RH was the most important local and regional meteorological factor. Therefore, similar to $\mathrm{SO}_{2}$, the influence of population growth and associated increases in anthropogenic activities in the north-eastern interior is also reflected in $\mathrm{NO}_{2}$ levels, while the impacts of increased household combustion associated with growing rural communities are also evident, especially at SK. The negative correlation to $\mathrm{RH}$ indicates higher $\mathrm{NO}_{2}$ levels associated with drier months, i.e. winter, which contribute to seasonal variances. ENSO was shown to make a significant contribution to modelled $\mathrm{O}_{3}$ levels at all three sites, while the important influence of local and regional meteorological factors was also evident, especially through significant negative correlations with $T$ and $\mathrm{RH}$ at $\mathrm{SK}$ and LT. Inter-annual $\mathrm{O}_{3}$ variability in this part of South Africa can therefore most likely be attributed to ENSO cycles, while seasonal patterns are attributed changes in local and regional meteorology.
The decreases in $\mathrm{SO}_{2}$ and $\mathrm{NO}_{2}$ concentrations from 1995 were attributed to the implementation of mitigation policies by industries following the establishment of the new democracy in South Africa. However, these improvements were offset from 2002 due to rapid economic growth associated with increased industrial activities, as well as the increase in population growth accompanied by higher energy demand. The 19-year trend lines for $\mathrm{SO}_{2}$ and $\mathrm{NO}_{2}$ at $\mathrm{AF}$ indicated an increase in $\mathrm{SO}_{2}$ and $\mathrm{NO}_{2}$ concentrations over the 19-year sampling period. In addition, an upward trend in $\mathrm{NO}_{2}$ levels was also evident at SK, signifying the influence of the growing rural communities on the border of the Kruger National Park. Marginal trends were observed for $\mathrm{SO}_{2}$ at $\mathrm{SK}$, as well as $\mathrm{SO}_{2}$ and $\mathrm{NO}_{2}$ at LT. Trend analysis of $\mathrm{O}_{3}$ at all three sites indicated that $\mathrm{O}_{3}$ concentrations remained relatively constant at all three sites for the entire 19-, 21- and 16-year sampling periods at $\mathrm{AF}, \mathrm{LT}$ and $\mathrm{SK}$, respectively.

As expected, $\mathrm{SO}_{2}$ and $\mathrm{NO}_{2}$ concentrations were higher at $\mathrm{AF}$ compared to levels thereof at the rural background sites LT and SK. $\mathrm{SO}_{2}$ levels at AF were similar to levels of these species determined with passive samplers at other sites within the Mpumalanga Highveld with the exception of sites closer to the major industrial sources. $\mathrm{NO}_{2}$ levels at $\mathrm{AF}$ were generally lower than $\mathrm{NO}_{2}$ concentrations determined at sites within the source region, as well as lower than regional sites in China. $\mathrm{SO}_{2}$ and $\mathrm{NO}_{2}$ concentrations determined at LT and SK were similar to levels thereof determined with passive samplers at regional and rural sites in Africa and other parts of the world. The regional problem of $\mathrm{O}_{3}$ in the interior of South Africa was also evident, with similar $\mathrm{O}_{3}$ levels determined at all three sites. 


\section{Appendix A}
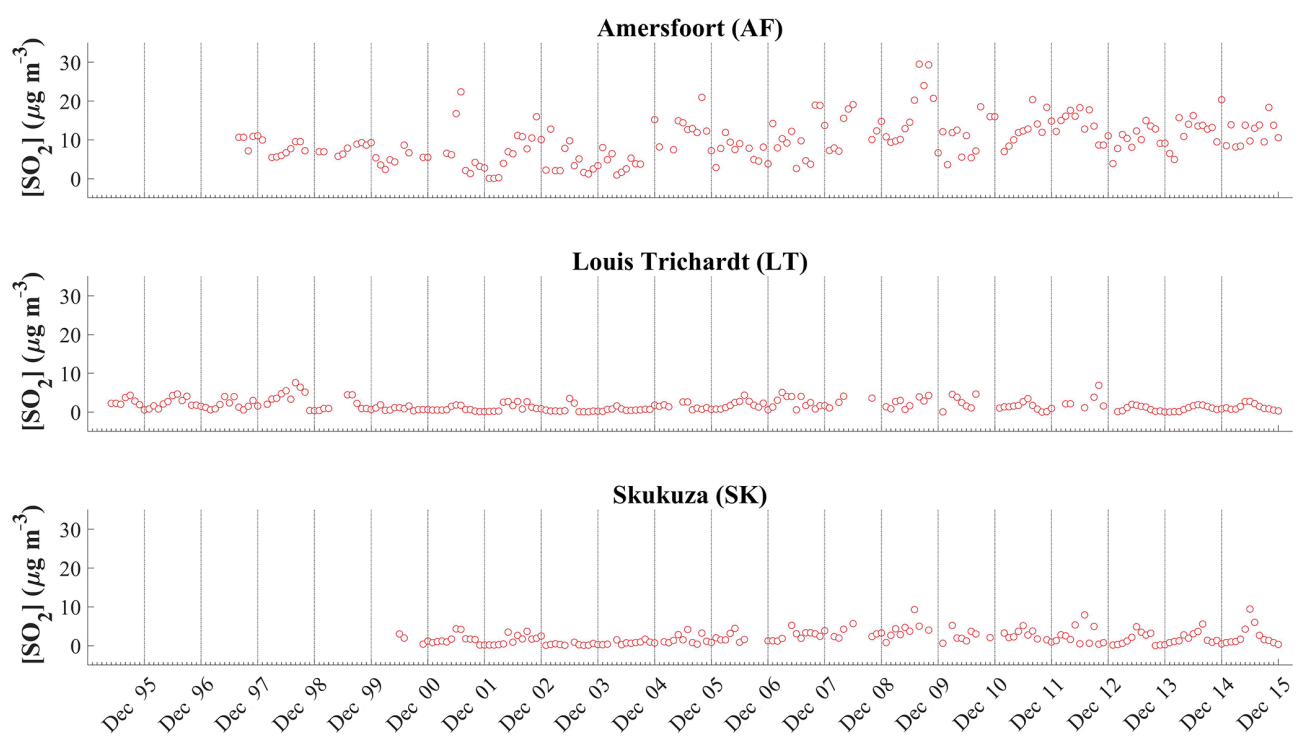

Figure A1. Time series of monthly average $\mathrm{SO}_{2}$ concentrations measured at Amersfoort (AF), Louis Trichardt (LT) and Skukuza (SK) using passive samplers over the relevant measurement periods.
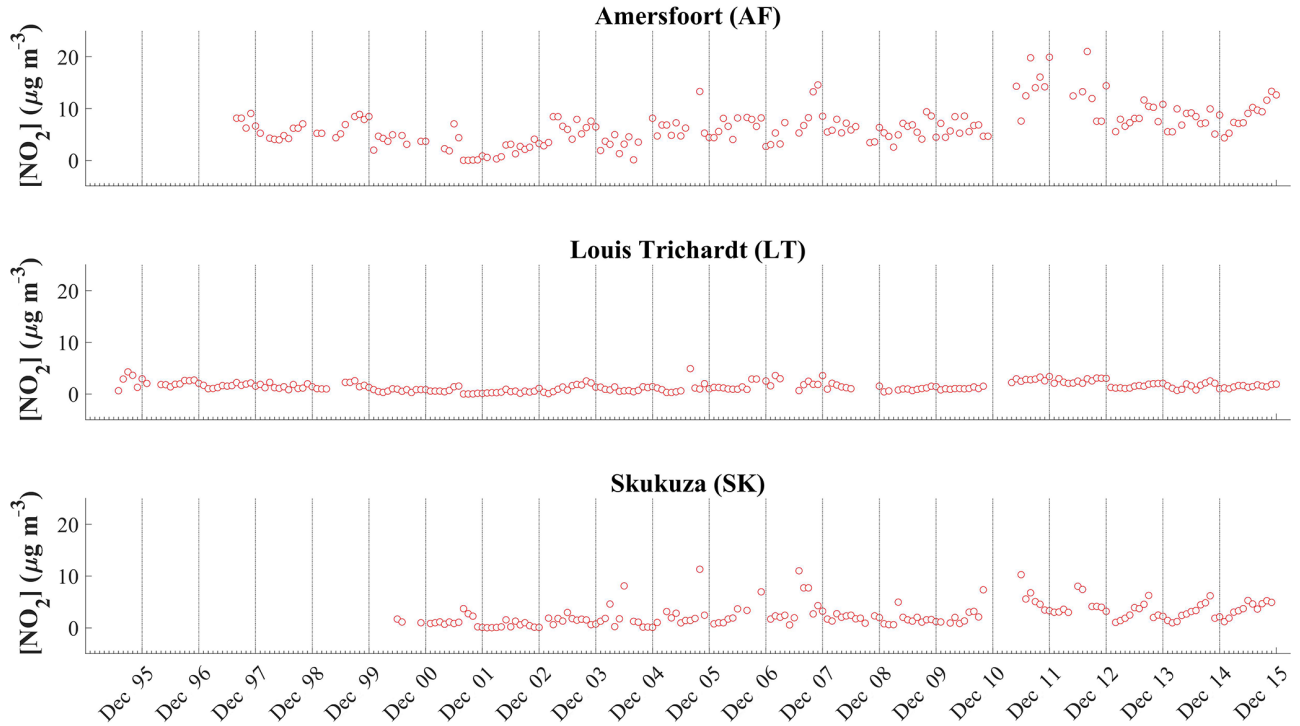

Figure A2. Time series of monthly average $\mathrm{NO}_{2}$ concentrations measured at Amersfoort (AF), Louis Trichardt (LT) and Skukuza (SK) using passive samplers over the relevant measurement periods. 

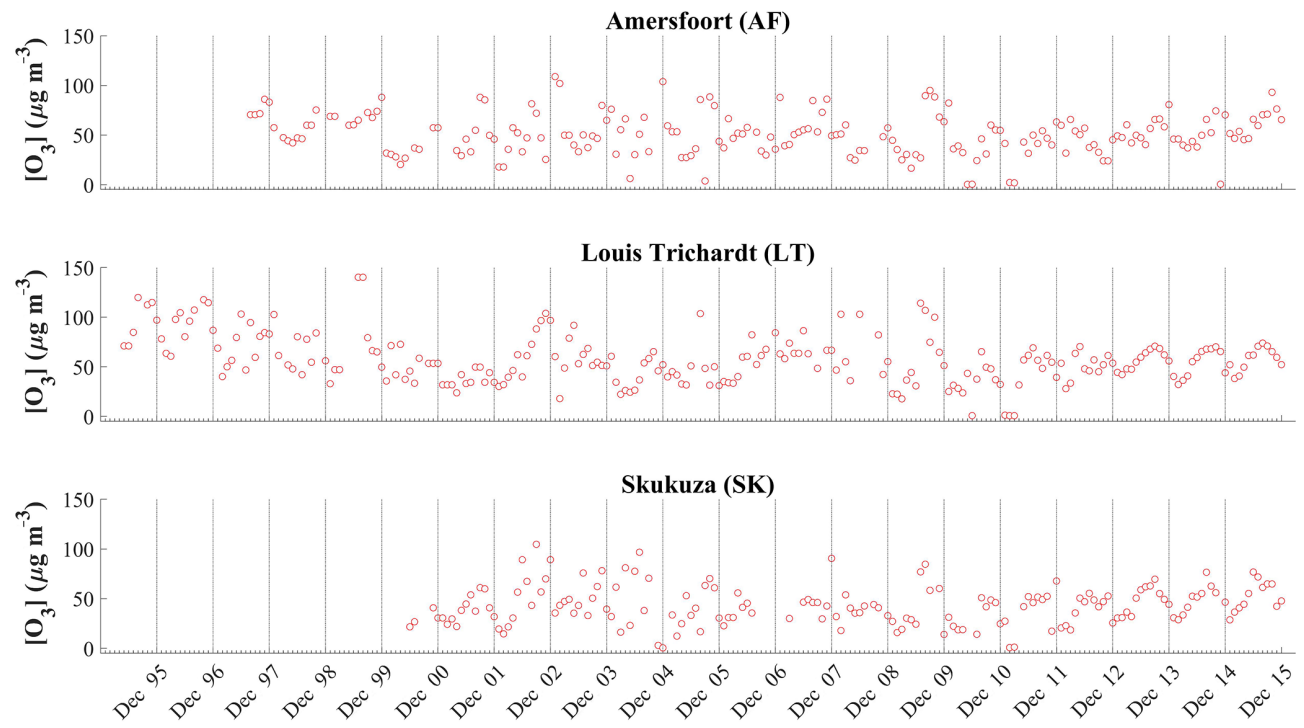

Figure A3. Time series of monthly average $\mathrm{O}_{3}$ concentrations measured at Amersfoort (AF), Louis Trichardt (LT) and Skukuza (SK) using passive samplers over the relevant measurement periods.

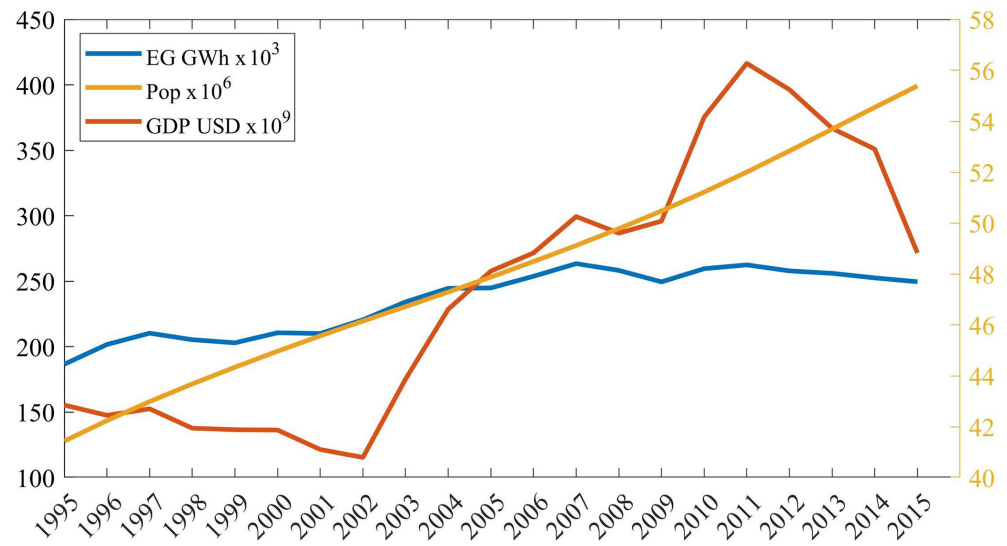

Figure A4. South African population (Pop) and GDP from 1995 to 2015 (World Bank, 2019), as well as electricity generation (EG) during this period (International Energy Agency, 2020). 


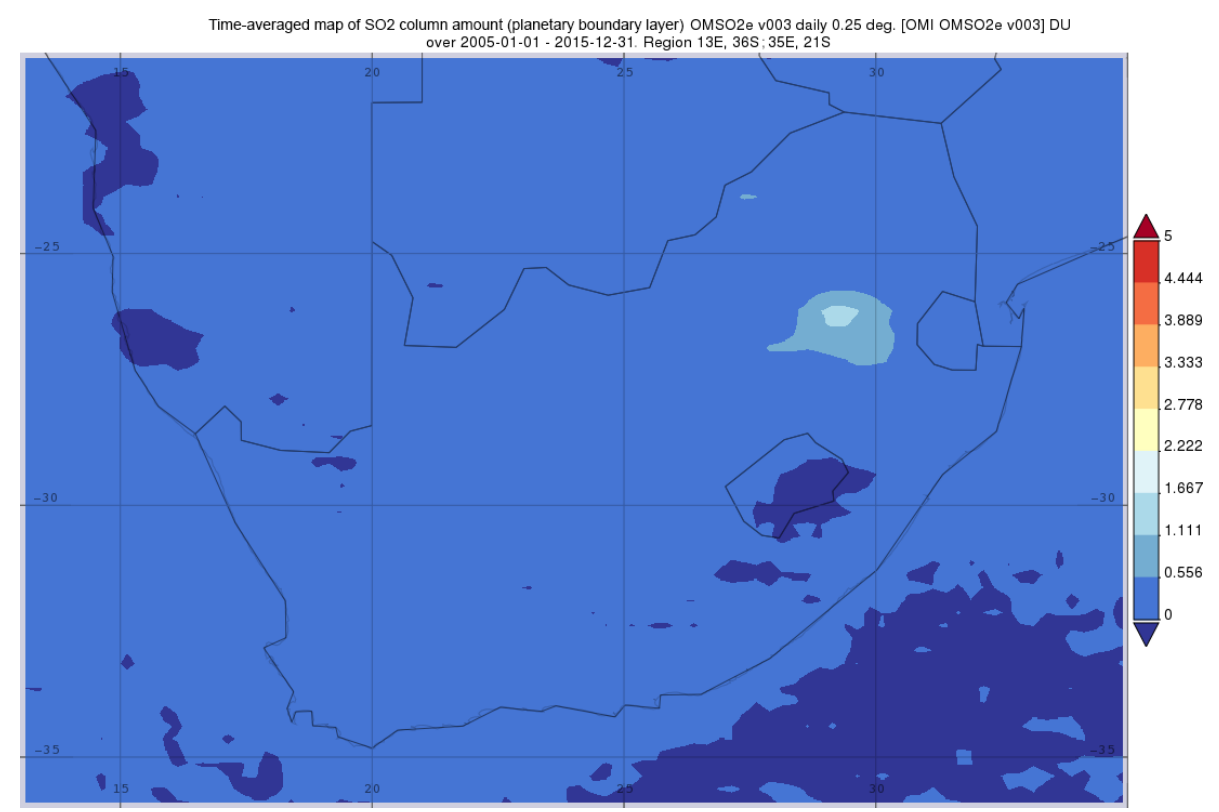

Figure A5. Geospatial map of southern Africa depicting the $\mathrm{SO}_{2}$ column amount averaged over the period 2005 to 2015 obtained using the data from the NASA Giovanni satellite (https://giovanni.gsfc.nasa.gov/giovanni/, last access: 20 June 2019). OMI: Aura Ozone Monitoring Instrument. OMSO2e v003: OMI Level-3e $\mathrm{SO}_{2}$ Data Product. DU: Dobson unit.

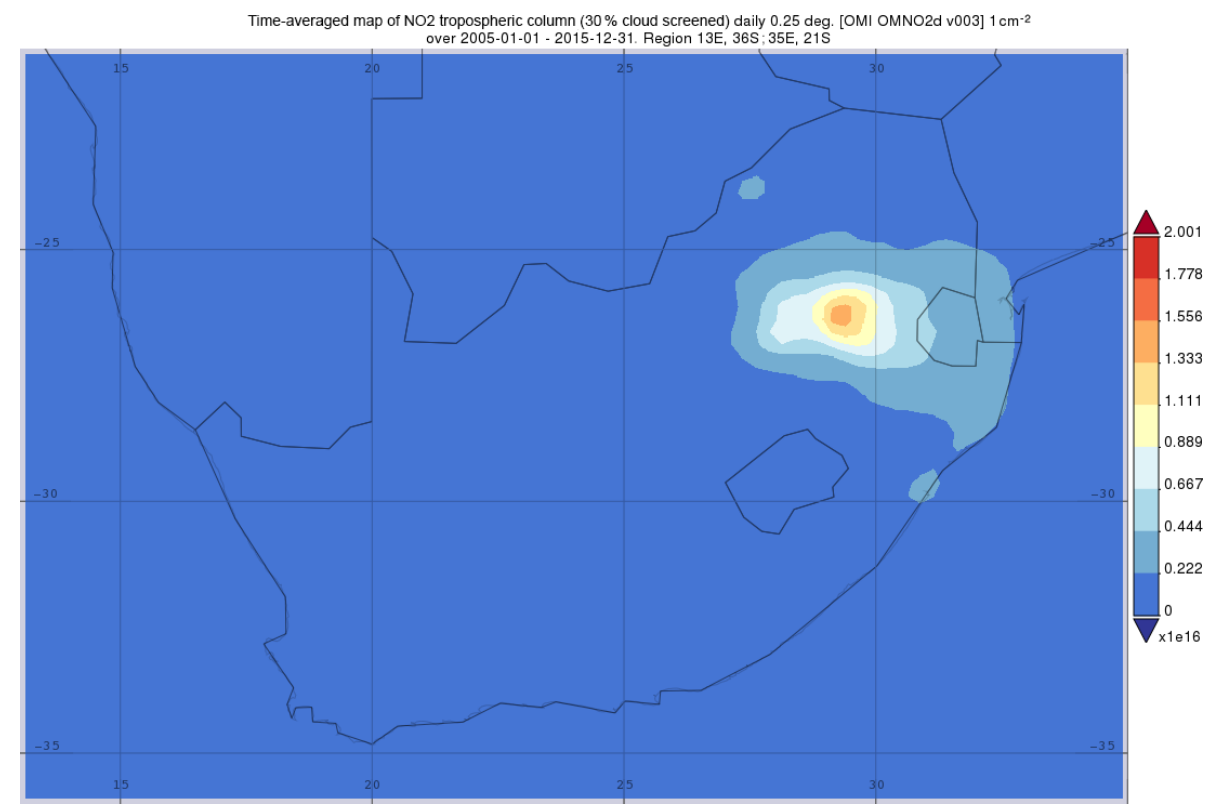

Figure A6. Geospatial map of southern Africa depicting the $\mathrm{NO}_{2}$ tropospheric column density averaged over the period 2005 to 2015 obtained using the data from the NASA Giovanni satellite (https://giovanni.gsfc.nasa.gov/giovanni/). OMI: Aura Ozone Monitoring Instrument. OMSO2e v003: OMI Level-3e $\mathrm{SO}_{2}$ Data Product. DU: Dobson unit. 
Data availability. The data of this paper are available upon request to Pieter G. van Zyl (pieter.vanzyl@nwu.ac.za) or Johan P. Beukes (paul.beukes@nwu.ac.za).

Author contributions. JSS, PGvZ and JPB were the main investigators in this study. PGvZ and JPB were project leaders of the study and wrote the paper. JSS conducted this study as part of his $\mathrm{PhD}$ degree and performed most of the experimental work and data processing. PGvZ and JPB were also study leaders of the PhD. AR assisted in sample collection and with financial support. CGL and JJP made conceptual contributions.

Competing interests. The authors declare that they have no conflict of interest.

Acknowledgements. The authors would like to thank the International Global Atmospheric Chemistry programme for endorsing the DEBITS programme, as well as Sasol and Eskom for financial support of the South African INDAAF project. Also acknowledged is assistance with sample deployment and collection by Carin van der Merwe and the site operators, who include Memory Deacon at AF; Chris James at LT; and Navashni Govender, Walter Kubheka, Eva Gardiner and Joel Tleane at SK.

Review statement. This paper was edited by Drew Gentner and reviewed by two anonymous referees.

\section{References}

Adon, M., Galy-Lacaux, C., Yoboué, V., Delon, C., Lacaux, J. P., Castera, P., Gardrat, E., Pienaar, J., Al Ourabi, H., Laouali, D., Diop, B., Sigha-Nkamdjou, L., Akpo, A., Tathy, J. P., Lavenu, F., and Mougin, E.: Long term measurements of sulfur dioxide, nitrogen dioxide, ammonia, nitric acid and ozone in Africa using passive samplers, Atmos. Chem. Phys., 10, 7467-7487, https://doi.org/10.5194/acp-10-7467-2010, 2010.

Adon, M., Galy-Lacaux, C., Delon, C., Yoboue, V., Solmon, F., and Kaptue Tchuente, A. T.: Dry deposition of nitrogen compounds $\left(\mathrm{NO}_{2}, \mathrm{HNO}_{3}, \mathrm{NH}_{3}\right)$, sulfur dioxide and ozone in west and central African ecosystems using the inferential method, Atmos. Chem. Phys., 13, 11351-11374, https://doi.org/10.5194/acp-13-113512013, 2013.

Balashov, N. V., Thompson, A. M., Piketh, S. J., and Langerman, K. E.: Surface ozone variability and trends over the South African Highveld from 1990 to 2007, J. Geophys. Res.-Atmos., 119, 4323-4342, https://doi.org/10.1002/2013JD020555, 2014.

Bencherif, H., Diab, R. D., Portafaix, T., Morel, B., Keckhut, P., and Moorgawa, A.: Temperature climatology and trend estimates in the UTLS region as observed over a southern subtropical site, Durban, South Africa, Atmos. Chem. Phys., 6, 5121-5128, https://doi.org/10.5194/acp-6-5121-2006, 2006.

Booyens, W., Beukes, J. P., Van Zyl, P. G., Ruiz-Jimenez, J., Kopperi, M., Riekkola, M.-L., Josipovic, M., Vakkari, V., and
Laakso, L.: Assessment of polar organic aerosols at a regional background site in southern Africa, J. Atmos. Chem., 76, 89113, https://doi.org/10.1007/s10874-019-09389-y, 2019.

Bytnerowicz, A., Tausz, M., Alonso, R., Jones, D., Johnson, R., and Grulke, N.: Summer-time distribution of air pollutants in Sequoia National Park, California, Environ. Pollut., 118, 187-203, https://doi.org/10.1016/S0269-7491(01)00312-8, 2002.

Carmichael, G. R., Ferm, M., Thongboonchoo, N., Woo, J.-H., Chan, L. Y., Murano, K., Viet, P. H., Mossberg, C., Bala, R., Boonjawat, J., Upatum, P., Mohan, M., Adhikary, S. P., Shrestha, A. B., Pienaar, J. J., Brunke, E. B., Chen, T., Jie, T., Guoan, D., Peng, L. C., Dhiharto, S., Harjanto, H., Jose, A. M., Kimani, W., Kirouane, A., Lacaux, J.-P., Richard, S., Barturen, O., Cerda, J. C., Athayde, A., Tavares, T., Cotrina, J. S., and Bilici, E.: Measurements of sulfur dioxide, ozone and ammonia concentrations in Asia, Africa, and South America using passive samplers, Atmos. Environ., 37, 1293-1308, https://doi.org/10.1016/S13522310(02)01009-9, 2003.

Connell, D. W.: Basic concepts of environmental chemistry, CRC Press, Boca Raton, Florida, USA, 2005.

Conradie, E. H., Van Zyl, P. G., Pienaar, J. J., Beukes, J. P., Galy-Lacaux, C., Venter, A. D., and Mkhatshwa, G. V.: The chemical composition and fluxes of atmospheric wet deposition at four sites in South Africa, Atmos. Environ., 146, 113-131, https://doi.org/10.1016/j.atmosenv.2016.07.033, 2016.

Dhammapala, R. S.: Use of diffusive samplers for the sampling of atmospheric pollutants, MSc, Potchefstroom University for CHE, Potchefstroom, South Africa, 1996.

Draxler, R. R. and Hess, G. D.: Description of the HYSPLIT_4 modelling system, 7th Edn., Silver Spring, Maryland: Air Resources Laboratory, 2014.

Ferm, M.: A Sensitive Diffusional Sampler, IVL Report L91, Göteborg, Sweden: Swedish Environmental Research Institute, 1991.

Fowler, D., Pilegaard, K., Sutton, M. A., Ambus, P., Raivonen, M., Duyzer, J., Simpson, D., Fagerli, H., Fuzzi, S., Schjoerring, J. K., Granier, C., Neftel, A., Isaksen, I. S. A., Laj, P., Maione, M., Monks, P. S., Burkhardt, J., Daemmgen, U., Neirynck, J., Personne, E., Wichink-Kruit, R., Butterbach-Bahl, K., Flechard, C., Tuovinen, J. P., Coyle, M., Gerosa, G., Loubet, B., Altimir, N., Gruenhage, L., Ammann, C., Cieslik, S., Paoletti, E., Mikkelsen, T. N., Ro-Poulsen, H., Cellier, P., Cape, J. N., Horváth, L., Loreto, F., Niinemets, Ü., Palmer, P. I., Rinne, J., Misztal, P., Nemitz, E., Nilsson, D., Pryor, S., Gallagher, M. W., Vesala, T., Skiba, U., Brüggemann, N., Zechmeister-Boltenstern, S., Williams, J., O'Dowd, C., Facchini, M. C., De Leeuw, G., Flossman, A., Chaumerliac, N., and Erisman, J. W.: Atmospheric composition change: EcosystemsAtmosphere interactions, Atmos. Environ., 43, 5193-5267, https://doi.org/10.1016/j.atmosenv.2009.07.068, 2009.

Garstang, M., Tyson, P. D., Swap, R., Edwards, M., Kållberg, P., and Lindesay, J. A.: Horizontal and vertical transport of air over southern Africa, J. Geophys. Res.-Atmos., 101, 23721-23736, https://doi.org/10.1029/95JD00844, 1996.

Gierens, R. T., Henriksson, S., Josipovic, M., Vakkari, V., Van Zyl, P. G., Beukes, J. P., Wood, C. R., and O'Connor, E. J.: Observing continental boundary-layer structure and evolution over the South African savannah using a ceilometer, Theor. Appl. Climatol., 136, 333-346, https://doi.org/10.1007/s00704-018-2484-7, 2019. 
He, J. and Bala, R.: Draft Report on passive sampler intercomparison under Malé declaration. Malé Declaration on Control and Prevention of Air Pollution and its Likely Transboundary Effect for South Asia, National University of Singapore, Singapore, 2008.

Hewitson, B. C. and Crane, R. G.: Consensus between GCM climate change projections with empirical downscaling: precipitation downscaling over South Africa, Int. J. Climatol., 26, 13151337, https://doi.org/10.1002/joc.1314, 2006.

ICDA (International Chromium Development Association): High carbon charge grade ferrochromium Statistics. Statistical Bulletin 2012, International Chromium Development Association, Paris, France, 2012.

ICDA: Statistical Bulletin 2013 (based on 2012 data), International Chromium Development Association, 2013.

Inglesi-Lotz, R. and Blignaut, J.: Estimating the price elasticity for demand for electricity by sector in South Africa, S. Afr. J. Econ. Manag. S., 14, 449-465, https://doi.org/10.4102/sajems.v14i4.134, 2011.

International Energy Agency: Data and statistics, available at: https://www.iea.org/data-and-statistics/data-tables?country= SOUTHAFRIC, last access: 14 May 2020.

ISO: ISO Survey, available at: http://www.iso.org/iso/iso-survey (last access: 23 January 2017), 2015.

Jaars, K., Beukes, J. P., van Zyl, P. G., Venter, A. D., Josipovic, M., Pienaar, J. J., Vakkari, V., Aaltonen, H., Laakso, H., Kulmala, M., Tiitta, P., Guenther, A., Hellén, H., Laakso, L., and Hakola, H.: Ambient aromatic hydrocarbon measurements at Welgegund, South Africa, Atmos. Chem. Phys., 14, 7075-7089, https://doi.org/10.5194/acp-14-7075-2014, 2014.

Josipovic, M., Annegarn, H. J., Kneen, M. A., Pienaar, J. J., and Piketh, S. J.: Atmospheric dry and wet deposition of sulphur and nitrogen species and assessment of critical loads of acidic deposition exceedance in South Africa, S. Afr. J. Sci., 107, 1-10, https://doi.org/10.4102/sajs.v107i3/4.478, 2011.

Kaufman, Y. J., Ichoku, C., Giglio, L., Korontzi, S., Chu, D. A., Hao, W. M., Li, R. R., and Justice, C. O.: Fire and smoke observed from the Earth Observing System MODIS instrument products, validation, and operational use, Int. J. Remote Sens., 24, 1765-1781, https://doi.org/10.1080/01431160210144741, 2003.

Kleynhans, E., Beukes, J. P., Van Zyl, P. G., Bunt, J., Nkosi, N., and Venter, M.: The Effect of Carbonaceous Reductant Selection on Chromite Pre-reduction, Metall. Mater. Trans. B, 48, 827-840, https://doi.org/10.1007/s11663-016-0878-4, 2017.

KMNI: Monthly DMI HadISST1, available at: http: //climexp.knmi.nl/getindices.cgi?WMO=UKMOData/hadisst1_ dmi\&STATION=DMI_HadISST1\&TYPE=i\&id=someone@ somewhere, last access: 22 December 2016a.

KMNI: Monthly measured total solar irradiance, available at: http://climexp.knmi.nl/getindices.cgi?WMO=PMODData/tsi\& STATION=measured_total_solar_irradiance $\&$ TYPE $=i \& i d=$ someone@ somewhere, last access: 22 December 2016b.

Korhonen, K., Giannakaki, E., Mielonen, T., Pfüller, A., Laakso, L., Vakkari, V., Baars, H., Engelmann, R., Beukes, J. P., Van Zyl, P. G., Ramandh, A., Ntsangwane, L., Josipovic, M., Tiitta, P., Fourie, G., Ngwana, I., Chiloane, K., and Komppula, M.: Atmospheric boundary layer top height in South Africa: measurements with lidar and radiosonde compared to three atmospheric models, Atmos. Chem. Phys., 14, 4263-4278, https://doi.org/10.5194/acp-14-4263-2014, 2014.

Kraha, A., Turner, H., Nimon, K., Reichwein Zientek, L., and Henson, R. K.: Tools to support interpreting multiple regression in the face of multicollinearity, Front. Psychol., 3, 1-16, https://doi.org/10.3389/fpsyg.2012.00044, 2012.

Laakso, L., Vakkari, V., Virkkula, A., Laakso, H., Backman, J., Kulmala, M., Beukes, J. P., van Zyl, P. G., Tiitta, P., Josipovic, M., Pienaar, J. J., Chiloane, K., Gilardoni, S., Vignati, E., Wiedensohler, A., Tuch, T., Birmili, W., Piketh, S., Collett, K., Fourie, G. D., Komppula, M., Lihavainen, H., de Leeuw, G., and Kerminen, V.-M.: South African EUCAARI measurements: seasonal variation of trace gases and aerosol optical properties, Atmos. Chem. Phys., 12, 1847-1864, https://doi.org/10.5194/acp12-1847-2012, 2012.

Laban, T. L., van Zyl, P. G., Beukes, J. P., Vakkari, V., Jaars, K., Borduas-Dedekind, N., Josipovic, M., Thompson, A. M., Kulmala, M., and Laakso, L.: Seasonal influences on surface ozone variability in continental South Africa and implications for air quality, Atmos. Chem. Phys., 18, 15491-15514, https://doi.org/10.5194/acp-18-15491-2018, 2018.

Lacaux, J. P., Tathy, J. P., and Sigha, L.: Acid wet deposition in the tropics: Two case studies using DEBITS measurements, IGACtivities Newsletter of the International Global Atmospheric Chemistry Project, The IGAC Core Project Office, Durham, New Hampshire, USA, 2003.

Lorenzo-Seva, U., Ferrando, P. J., and Chico, E.: Two SPSS programs for interpreting multiple regression results, Behav. Res. Methods, 42, 29-35, https://doi.org/10.3758/BRM.42.1.29, 2010.

Lourens, A. S., Beukes, J. P., Van Zyl, P. G., Fourie, G. D., Burger, J. W., Pienaar, J. J., Read, C. E., and Jordaan, J. H.: Spatial and temporal assessment of gaseous pollutants in the Highveld of South Africa, S. Afr. J. Sci., 107, 1-8, https://doi.org/10.4102/sajs.v107i1/2.269, 2011.

Maritz, P., Beukes, J. P., Van Zyl, P. G., Liousse, C., Gardrat, E., Ramandh, A., and Mkhatshwa, G. V.: Temporal and source assessments of organic and elemental carbon at sites in the northern South African interior, J. Atmos. Chem., 76, 263-287, https://doi.org/10.1007/s10874-020-09398-2, 2019.

Marshall, G.: An observation-based Southern Hemisphere Annular Mode Index, United Kingdom, available at: http://www.nerc-bas. ac.uk/icd/gjma/sam.html, last access: 28 August 2018.

Martins, J. J., Dhammapala, R. S., Lachmann, G., Galy-Lacaux, C., and Pienaar, J. J.: Long-term measurements of sulphur dioxide, nitrogen dioxide, ammonia, nitric acid and ozone in southern Africa using passive samplers, S. Afr. J. Sci., 103, 336-342, 2007.

Meng, Z.-Y., Xu, X.-B., Wang, T., Zhang, X.-Y., Yu, X.L., Wang, S.-F., Lin, W.-L., Chen, Y.-Z., Jiang, Y.-A., and An, X.-Q.: Ambient sulfur dioxide, nitrogen dioxide, and ammonia at ten background and rural sites in China during 2007-2008, Atmos. Environ., 44, 2625-2631, https://doi.org/10.1016/j.atmosenv.2010.04.008, 2010.

Meth, O.: New satellite data reveals the world's largest air pollution hotspot is Mpumalanga - South Africa, available at: https://www.greenpeace.org/africa/en/press/4202/newsatellite-data-reveals-the-worlds-largest-air-pollution-hotspot- 
is-mpumalanga-south-africa/ (last access: 17 January 2019), 2018.

Monks, P. S., Granier, C., Fuzzi, S., Stohl, A., Williams, M. L., Akimoto, H., Amann, M., Baklanov, A., Baltensperger, U., Bey, I., Blake, N., Blake, R. S., Carslaw, K., Cooper, O. R., Dentener, F., Fowler, D., Fragkou, E., Frost, G. J., Generoso, S., Ginoux, P., Grewe, V., Guenther, A., Hansson, H. C., Henne, S., Hjorth, J., Hofzumahaus, A., Huntrieser, H., Isaksen, I. S. A., Jenkin, M. E., Kaiser, J., Kanakidou, M., Klimont, Z., Kulmala, M., Laj, P., Lawrence, M. G., Lee, J. D., Liousse, C., Maione, M., Mcfiggans, G., Metzger, A., Mieville, A., Moussiopoulos, N., Orlando, J. J., O'dowd, C. D., Palmer, P. I., Parrish, D. D., Petzold, A., Platt, U., Pöschl, U., Prévôt, A. S. H., Reeves, C. E., Reimann, S., Rudich, Y., Sellegri, K., Steinbrecher, R., Simpson, D., Ten Brink, H., Theloke, J., Van Der Werf, G. R., Vautard, R., Vestreng, V., Vlachokostas, C., and Von Glasow, R.: Atmospheric composition change - global and regional air quality, Atmos. Environ., 43, 5268-5350, https://doi.org/10.1016/j.atmosenv.2009.08.021, 2009.

Mphepya, J. N., Pienaar, J. J., Galy-Lacaux, C., Held, G., and Turner, C. R.: Precipitation Chemistry in SemiArid Areas of Southern Africa: A Case Study of a Rural and an Industrial Site, J. Atmos. Chem., 47, 1-24, https://doi.org/10.1023/B:JOCH.0000012240.09119.c4, 2004.

Mphepya, J. N., Galy-Lacaux, C., Lacaux, J. P., Held, G., and Pienaar, J. J.: Precipitation Chemistry and Wet Deposition in Kruger National Park, South Africa, J. Atmos. Chem., 53, 169-183, https://doi.org/10.1007/s10874-005-9005-7, 2006.

Nathans, L. L., Oswald, F. L., and Nimon, K.: Interpreting Multiple Linear Regression: A Guidebook of Variable Importance, Pract. Assess. Res. Evaluation, 17, 1-19, 2012.

NOAA: Climate Indices: Monthly Atmospheric and Ocean Time Series, available at: https://www.esrl.noaa.gov/psd/data/ climateindices/list/ (last access: 22 December 2016), 2015a.

NOAA: Monthly Atmospheric and SST Indices, available at: http:// www.cpc.ncep.noaa.gov/data/indices/ (last access: 22 December 2016), 2015b.

Rorich, R. P. and Galpin, J. S.: Air quality in the Mpumalanga Highveld region, South Africa, S. Afr. J. Sci., 94, 109-114, 1998.

Sheskin, D. J.: Handbook of Parametric and Nonparametric Statistical Procedures, Boca Raton, Chapman and Hall/CRC Press, 2003.
Statistics South Africa: National Accounts: Energy Accounts for South Africa: 2002-2009, Pretoria, Statistics South Africa, 2012.

Swartz, J.-S., Van Zyl, P. G., Beukes, J. P., Labuschagne, C., Brunke, E.-G., Portafaix, T., Galy-Lacaux, C., and Pienaar, J. J.: Twentyone years of passive sampling monitoring of $\mathrm{SO}_{2}, \mathrm{NO}_{2}$ and $\mathrm{O}_{3}$ at the Cape Point GAW station, South Africa, Atmos. Environ., 222, 117128, https://doi.org/10.1016/j.atmosenv.2019.117128, 2020.

Tiitta, P., Vakkari, V., Croteau, P., Beukes, J. P., van Zyl, P. G., Josipovic, M., Venter, A. D., Jaars, K., Pienaar, J. J., Ng, N L., Canagaratna, M. R., Jayne, J. T., Kerminen, V.-M., Kokkola, H., Kulmala, M., Laaksonen, A., Worsnop, D. R., and Laakso, L.: Chemical composition, main sources and temporal variability of $\mathrm{PM}_{1}$ aerosols in southern African grassland, Atmos. Chem. Phys., 14, 1909-1927, https://doi.org/10.5194/acp-141909-2014, 2014.

Toihir, A. M., Portafaix, T., Sivakumar, V., Bencherif, H., Pazmiño, A., and Bègue, N.: Variability and trend in ozone over the southern tropics and subtropics, Ann. Geophys., 36, 381-404, https://doi.org/10.5194/angeo-36-381-2018, 2018.

Tyson, P. D., Garstang, M., and Swap, R.: LargeScale Recirculation of Air over Southern Africa, J. Appl. Meteorol., 35, 18, https://doi.org/10.1175/15200450(1996)035<2218:LSROAO>2.0.CO;2, 1996.

Vet, R., Artz, R. S., Carou, S., Shaw, M., Ro, C.-U., Aas, W., Baker, A., Bowersox, V. C., Dentener, F., Galy-Lacaux, C., Hou, A., Pienaar, J. J., Gillett, R., Forti, M. C., Gromov, S., Hara, H., Khodzher, T., Mahowald, N. M., Nickovic, S., Rao, P. S. P., and Reid, N. W.: A global assessment of precipitation chemistry and deposition of sulfur, nitrogen, sea salt, base cations, organic acids, acidity and pH, and phosphorus, Atmos. Environ., 93, 3100, https://doi.org/10.1016/j.atmosenv.2013.10.060, 2014.

Westcott, G., Tacke, M., Schoeman, N., and Morgan, N.: Impala Platinum Smelter, Rustenburg: An integrated smelter off-gas treatment solution, J. S. Afr. I. Min. Metall., 107, 281-287, 2007.

World Bank: Data, available at: https://data.worldbank.org/country/ south-africa (last access: 15 May 2020), 2019. 